\title{
Truncated denitrifiers dominate the denitrification pathway in tundra soil metagenomes
}

\author{
Igor S. Pessi ${ }^{1,2}$, Sirja Viitamäki ${ }^{1}$, Anna-Maria Virkkala ${ }^{3,4}$, Eeva Eronen-Rasimus ${ }^{1,5}$, \\ Tom O. Delmont ${ }^{6}$, Maija E. Marushchak ${ }^{7,8}$, Miska Luoto $^{3}$ and Jenni Hultmann ${ }^{1,2, *}$
}

${ }^{1}$ Department of Microbiology, University of Helsinki, Helsinki, Finland

${ }^{2}$ Helsinki Institute of Sustainability Science (HELSUS), Helsinki, Finland

${ }^{3}$ Department of Geosciences and Geography, University of Helsinki, Helsinki, Finland

${ }^{4}$ Woodwell Climate Research Center, Falmouth, MA, USA

${ }^{5}$ Marine Research Centre, Finnish Environment Institute (SYKE), Helsinki, Finland

${ }^{6}$ Department of Bioinformatics, Genoscope, Paris, France

${ }^{7}$ Department of Biological and Environmental Science, University of Jyväskylä, Finland

${ }^{8}$ Department of Environmental and Biological Sciences, University of Eastern Finland, Kuopio, Finland

*Corresponding author: jenni.hultman@helsinki.fi

\section{Abstract}

In contrast to earlier assumptions, there is now mounting evidence for the role of tundra soils as important sources of the greenhouse gas nitrous oxide $\left(\mathrm{N}_{2} \mathrm{O}\right)$. However, the microorganisms involved in the cycling of $\mathrm{N}_{2} \mathrm{O}$ in this system remain largely uncharacterized. In this study, we manually binned and curated 796 metagenome-assembled genomes (MAGs) from tundra soils in northern Finland, covering a wide range of ecosystems from dry heathlands to water-logged fens. We then searched for MAGs harbouring genes involved in denitrification, an important biotic process driving $\mathrm{N}_{2} \mathrm{O}$ emissions. Communities of potential denitrifiers differed across soil ecosystems but all were dominated by poorly characterized taxa with truncated denitrification pathways, i.e. lacking one or more denitrification genes. Water-logged fens were dominated by poorly known microorganisms affiliated with the Chloroflexota lineage Ellin6529 and the Acidobacteriota subdivision Gp23. Reanalysis of a previously published metagenomic dataset from soils in northern Sweden suggests that truncated denitrifiers are dominant throughout the tundra biome. With the support of in situ measurements of $\mathrm{N}_{2} \mathrm{O}$ fluxes, we hypothesize that truncated denitrifiers contribute significantly to the cycling of $\mathrm{N}_{2} \mathrm{O}$ in tundra soils. 


\section{Introduction}

Nitrous oxide $\left(\mathrm{N}_{2} \mathrm{O}\right)$ is a greenhouse gas (GHG) that has approximately 300 times the global warming potential of carbon dioxide on a 100-year scale [1]. Atmospheric $\mathrm{N}_{2} \mathrm{O}$ concentrations have increased by nearly $20 \%$ since pre-industrial times, with soils - both natural and anthropogenic - accounting for up to 70\% of the global emissions [2]. Despite being nitrogen (N) limited and enduring low temperatures throughout most of the year, tundra soils are increasingly recognized as important sources of $\mathrm{N}_{2} \mathrm{O}$ [3-7]. The relative contribution of tundra soils to global GHG emissions is predicted to increase in the future [8,9], as the warming rate at high latitude environments is more than twice as high than in tropical and temperate regions [10].

Microbial denitrification is an important biotic source of $\mathrm{N}_{2} \mathrm{O}$ [11]. Denitrification is a series of enzymatic steps in which soluble nitrate $\left(\mathrm{NO}_{3}{ }^{-}\right)$or nitrite $\left(\mathrm{NO}_{2}{ }^{-}\right)$are sequentially reduced to the gaseous products nitric oxide $(\mathrm{NO}), \mathrm{N}_{2} \mathrm{O}$, and dinitrogen $\left(\mathrm{N}_{2}\right)$. The denitrification trait is common across a wide range of archaea, bacteria, and fungi, most of which are facultative anaerobes that switch to $\mathrm{N}$ oxides as electron acceptors in anoxic conditions [12]. Denitrification has been traditionally known as a modular community process performed in synergy by different microbial taxa that execute only a subset of the complete denitrification pathway [12, 13]. With the growing number of microbial genomes sequenced in recent decades, it has become evident that only a fraction of the microorganisms involved in the denitrification pathway encode the enzymatic machinery needed for complete denitrification $[14,15]$. For instance, a study that investigated 652 genomes of cultured microorganisms containing denitrification genes showed that only approximately $31 \%$ encode the full set of enzymes needed for complete denitrification [14].

Compared to high $\mathrm{N}_{2} \mathrm{O}$-emitting systems such as agricultural and tropical soils, our knowledge of denitrifier communities in tundra soils is limited. As denitrification potentially results in the loss of $\mathrm{N}$ to the atmosphere, it enhances the N-limited status of tundra systems thus impacting both microbial and plant productivity [16, 17]. Investigations of denitrifier diversity in the tundra have been largely limited to gene-centric surveys using microarrays, amplicon sequencing, qPCR, and read-based metagenomics, which provide limited information on the taxonomic identity and genomic composition of community members. These studies have shown that tundra denitrifier communities are dominated by members of the Proteobacteria, Actinobacteria, and Bacteroidetes, and that the potential for complete denitrification is usually present at the community level [18-22]. However, it is not known whether the complete 
denitrification potential occurs within discrete microbial populations or is widespread throughout populations of truncated denitrifiers.

A better understanding of the ecological, metabolic, and functional traits of denitrifiers is critical for improving current models and mitigating $\mathrm{N}_{2} \mathrm{O}$ emissions [23]. This invariably relies on the characterization of the so-called uncultured majority, i.e. microorganisms that have not been cultured to date but which comprise a high proportion of the microbial diversity in complex ecosystems [24, 25]. Genome-resolved metagenomics is a powerful tool to access the genomes of uncultured microorganisms and has provided important insights into carbon cycling processes in tundra soils [26-28]. However, it has not yet been applied to investigate the mechanisms driving $\mathrm{N}_{2} \mathrm{O}$ cycling in the tundra. Here, we used genome-resolved metagenomics to obtain a more in-depth picture of the diversity and metabolic capabilities of potential denitrifiers in tundra soils. We analysed $1.4 \mathrm{~Tb}$ and $21.5 \mathrm{~Gb}$ of metagenomic reads from 69 soil samples taken from different ecosystems in an area of mountain tundra biome in Kilpisjärvi, northern Finland. By linking denitrification genes to specific microbial populations, we show that denitrifier communities in the tundra are dominated by microorganisms with truncated denitrification pathways, i.e. harbouring only a subset of the genes required for complete denitrification. By coupling an in-depth characterization of denitrifier communities with in situ measurements of $\mathrm{N}_{2} \mathrm{O}$ fluxes, we hypothesize that $\mathrm{N}_{2} \mathrm{O}$ cycling in tundra soils is driven primarily by microorganisms with truncated denitrification pathways.

\section{Methods}

\section{Study area and sampling for metagenomic analysis}

The Saana Nature Reserve $\left(69.04^{\circ} \mathrm{N}, 20.79^{\circ} \mathrm{E}\right)$ is located in Kilpisjärvi, northern Finland (Suppl. Fig. S1a). The area is part of the mountain tundra biome and is characterized by a mean annual temperature of $-1.9^{\circ} \mathrm{C}$ and annual precipitation of $487 \mathrm{~mm}$ [29]. Our study sites are distributed across Mount Saana and Mount Korkea-Jehkas and the valley in between (Suppl. Fig. S1b), and include barren soils, heathlands (dominated by evergreen and deciduous shrubs), meadows (dominated by graminoids and forbs), and fens (Suppl. Fig. S1c). In previous studies, we have established in the area a systematic fine-scale sampling of microclimate, soil conditions, and vegetation in topographically distinct environments [30-32]. Local variation in topography and soil properties creates a mosaic of habitats characterized by contrasting ecological conditions. This makes the study setting ideal to investigate species-environment relationships and ecosystem functioning in the tundra [32-34]. 
Sampling for metagenomic analysis was performed across 43 sites (barren soils, $\mathrm{n}=2$; heathlands, $\mathrm{n}=18$; meadows, $\mathrm{n}=7$; fens, $\mathrm{n}=16$ ) in July 2017 and July 2018, during the growing season in the northern hemisphere. Samples were obtained with a soil corer sterilized with $70 \%$ ethanol and, when possible, cores were split into organic and mineral samples using a sterilized spatula. In total, 41 organic and 28 mineral samples were obtained for metagenomic analysis (Suppl. Table S1). Samples were transferred to a whirl-pack bag and immediately frozen in dry ice. Samples were transported frozen to the laboratory at the University of Helsinki and kept at $-80^{\circ} \mathrm{C}$ until analyses.

\section{Soil physicochemical characterization and in situ measurement of GHG fluxes}

Soil physicochemical characterization was done using an extended set of 228 sites distributed across the study area. Soil pH, moisture, and soil organic matter (SOM) content were measured according to Finnish (SFS) and international (ISO) standards (SFS 300, ISO 10390, and SFS 3008). Carbon (C) and $\mathrm{N}$ content were measured using a Vario Micro Cube machine (Elementar, Langenselbold, Germany).

In situ ecosystem-level $\mathrm{N}_{2} \mathrm{O}$ and methane $\left(\mathrm{CH}_{4}\right)$ fluxes were measured from 101 sites using a static, non-steady state, non-flow-through system composed of a darkened acrylic chamber (20 $\mathrm{cm}$ diameter, $25 \mathrm{~cm}$ height) $[4,35]$. Measurements were conducted between $2^{\text {nd }}$ July and $2^{\text {nd }}$ August 2018, between 10 am and $5 \mathrm{pm}$. At each site, five $25 \mathrm{~mL}$ gas samples were taken during a 50-minute chamber closure and transferred to evacuated Exetainer vials (Labco, Lampeter, UK). Gas samples were analysed using an Agilent 7890B gas chromatograph (Agilent Technologies, Santa Clara, CA, USA) equipped with an autosampler (Gilson, Middleton, WI, USA) and a flame ionization detector for $\mathrm{CH}_{4}$ and an electron capture detector for $\mathrm{N}_{2} \mathrm{O}$. Gas concentrations were calculated from the gas chromatograph peak areas based on standard curves with a $\mathrm{CH}_{4}$ concentration of $0-100 \mathrm{ppm}$ and a $\mathrm{N}_{2} \mathrm{O}$ concentration of 0-5000 ppb.

\section{Metagenome sequencing and processing of raw data}

Total DNA and RNA were co-extracted as previously described [32]. Briefly, extraction was performed on $0.5 \mathrm{~g}$ of soil using a hexadecyltrimethyl ammonium bromide (CTAB), phenolchloroform, and bead-beating protocol. DNA was purified using the AllPrep DNA Mini Kit (QIAGEN, Hilden, Germany) and quantified using the Qubit dsDNA BR Assay Kit (ThermoFisher Scientific, Waltham, MA, USA). Library preparation for Illumina metagenome sequencing was performed using the Nextera XT DNA Library Preparation Kit (Illumina, San Diego, CA, USA). Metagenomes were obtained for 69 samples across two paired-end NextSeq 
(132-170 bp) and one NovaSeq (2 x 151 bp) runs (Suppl. Table S1). Two samples were additionally sequenced with Nanopore MinION. For this, libraries were prepared using the SQK-LSK109 Ligation Sequencing Kit with the long fragment buffer (Oxford Nanopore Technologies, Oxford, UK) and the NEBNext Companion Module for Oxford Nanopore Technologies Ligation Sequencing Kit (New England Biolabs). Each sample was sequenced for 48 hours on one R9.4 flow cell.

The quality of the raw Illumina data was verified with fastQC v0.11.9 [36] and multiQC v1.8 [37]. Cutadapt v1.16 [38] was then used to trim 3' adapters and low-quality base calls $(q<20)$ and to filter out short reads $(<50 \mathrm{bp})$. Nanopore data were basecalled with GPU guppy v4.0.11 using the high-accuracy model and applying a minimum quality score of 7 . The quality of the basecalled Nanopore data was assessed with pycoQC v2.5.0.21 [39] and adapters were trimmed with Porechop v0.2.4 [40].

\section{Read-based analyses}

Taxonomic and functional profiles of the microbial communities were obtained using a readbased approach, i.e. based on unassembled Illumina data. Due to differences in sequencing depth across the samples, the dataset was resampled to 2,000,000 reads per sample with seqtk v1.3 [41]. Taxonomic profiles were obtained by annotating SSU rRNA gene sequences against the SILVA database release 111 [42] with METAXA v2.2 [43]. Functional profiles were obtained by blastx searches against the KEGG database release 86 [44] with DIAMOND v0.9.14 [45]. Only matches with a maximum e-value of $10^{-5}$ and minimum identity of $60 \%$ were considered. The KEGG Orthology (KO) identifier of the best hit was assigned to each read and KEGG modules were summarised with the package keggR v0.9.1 [46] in R v3.6.3 [47]. Differences in taxonomic and functional community structure were assessed using non-metric multidimensional scaling (NMDS) and permutational ANOVA (PERMANOVA) with the package vegan v2.5.6 [48] in $\mathrm{R}$ v3.6.3 [47] (functions metaMDS and adonis, respectively). Differences in richness (i.e. the number of genera and functional genes) between the ecosystems were assessed using one-way analysis of variance (ANOVA) followed by Tukey's HSD test with the $l m$, aov, and TukeyHSD functions in R v3.6.3 [47]. The same tests were performed to assess differences in the abundance of individual genes across soil ecosystems, with p-values adjusted to control for false discovery rates. Relationships between the abundance of denitrification genes and $\mathrm{N}_{2} \mathrm{O}$ flux rates were assessed using linear regression in $\mathrm{R}$ v3.6.3[47] (functions $l m$ and $a o v$ ). 


\section{Metagenome assembling and binning}

Metagenome assembling of the Illumina data was performed as two co-assemblies. One coassembly comprised the upland soils (barren, heathland, and meadow; $n=47$ ) and the other the fen samples $(n=22)$. For each co-assembly, reads from the respective samples were pooled and assembled with MEGAHIT v1.1.1.2 [49]. Assembling of the Nanopore data was done for each sample individually with metaFlye v2.7.1 [50], and contigs were corrected based on Illumina data from the respective sample with bowtie v2.3.5 [51], SAMtools v1.9 [52], and pilon v1.23 [53]. Quality assessment of the (co-)assemblies was obtained with metaQUAST v5.0.2 [54].

Binning of metagenome-assembled genomes (MAGs) was performed separately for each Illumina and Nanopore (co-)assembly with anvi'o v6.2 [55] after discarding contigs shorter than $2500 \mathrm{bp}$. Gene calls were predicted with prodigal v2.6.3 [56]. Single-copy genes were identified with HMMER v.3.2.1 [57] and classified with DIAMOND v0.9.14 [45] against the Genome Taxonomy Database (GTDB) release 04-RS89 [58, 59]. Illumina reads were mapped to the contigs with bowtie v2.3.5 [51] and SAM files were sorted and indexed using SAMtools v1.9 [52]. Due to their large sizes, Illumina co-assemblies were split into 100 smaller clusters based on differential coverage and tetranucleotide frequency with CONCOCT v1.0.0 [60]. Contigs were then manually sorted into bins based on the same composition and coverage metrics using the anvi-interactive interface in anvi'o v6.2 [55]. Nanopore contigs were binned directly without preclustering. Bins that were $\geq 50 \%$ complete according to the presence of single-copy genes were further refined using the anvi-refine interface in anvi'o v6.2 [55]. In addition to taxonomic signal (based on single-copy genes classified against GTDB), either differential coverage or tetranucleotide frequency was used to identify and remove outlying contigs. The former was used for bins with a large variation in contig coverage across samples, and the latter for those with marked differences in GC content across contigs. Bins $\geq 50 \%$ complete and $\leq 10 \%$ redundant - hereafter referred as MAGs - were kept for downstream analyses.

\section{Phylogenomic analyses of MAGs and metabolic reconstruction}

Phylogenetic placement of MAGs was done based on 122 archaeal and 120 bacterial single-copy genes with GTDB-Tk v1.3.0 [61] and the GTDB release 05-RS95 [58, 59]. Acidobacteriota MAGs containing denitrification genes were submitted to further phylogenomic analyses alongside all genomes of Acidobacteriota strains and candidate taxa available on GenBank ( $\mathrm{n}=69$; accessed on 9 October 2020). For this, the amino acid sequence of 23 ribosomal proteins was retrieved for each genome with anvi'o v6.2 [55] and aligned with MUSCLE v3.8.1551 [62]. A maximum 
likelihood tree was then computed based on the concatenated alignments with FastTree v2.1.11 [63]. Escherichia coli ATCC 11775 was used to root the tree.

For metabolic reconstruction, MAGs were annotated against the KOfam hidden Markov model (HMM) database [64] with HMMER v.3.2.1 [57] using the pre-computed score thresholds of each HMM profile. The anvi-estimate-metabolism program in anvi'o v6.2 [55] was then used to predict the metabolic capabilities of the MAGs. A metabolic pathway was considered present in MAGs containing at least $75 \%$ of the genes involved in the pathway. Carbohydrate-active enzymes (CAZymes) were annotated with dbCAN v.2.0 based on the dbCAN v7 HMM database [65]. Only hits with an e-value $<1 \times 10^{-14}$ and coverage $>0.35$ were considered.

\section{Annotation of genes involved in denitrification}

MAGs were screened for genes involved in denitrification (nirK, nirS, nor $B$, and nos $Z$ ) using a three-step approach. First, predicted amino acid sequences were searched against the KOfam HMM database with KofamScan v1.3.0 [64]. Only matches with scores above the pre-computed family-specific thresholds were kept. Sequences were then inspected for the presence of conserved residues at the following positions: nirK, Cu-binding and active sites [66]; nirS, c-heme and $\mathrm{d}_{1}$-heme binding sites [67]; norB, binding of the catalytic centres cyt $\mathrm{b}$, $\mathrm{b}_{3}$, and $\mathrm{Fe}_{\mathrm{b}}$ [68]; nosZ: binding of the $\mathrm{Cu}_{\mathrm{z}}$ and $\mathrm{Cu}_{\mathrm{A}}$ centres [68]. For this, amino acid sequences were aligned with MAFFT v7.429 [69] and alignments were visualized with Unipro UGENE v38.1 [70]. Sequences which did not contain the correct amino acid at the aforementioned positions were removed. Finally, resulting amino acid sequences were aligned with MAFFT v7.429 [69] along with reference sequences from Graf et al. [14] and a maximum-likelihood tree was computed with FastTree v2.1.11 [63] using the LG+GAMMA model. Annotation of denitrification genes was also performed for previously published genomes retrieved from GenBank. These included a set of 1529 metagenome-assembled genomes (MAGs) obtained from soils in Stordalen Mire, northern Sweden [28] and the GenBank Acidobacteriota genomes described above.

\section{MAG dereplication and read recruitment analysis}

Prior to read recruitment analyses, Illumina and Nanopore MAGs were dereplicated based on a 90\% average nucleotide identity (ANI) threshold with fastANI v1.3 [71] to remove redundancy (i.e. MAGs that were recovered multiple times across the different assemblies). Read recruitment analyses were then then performed with CoverM [72]. For this, Illumina reads were mapped to the set of non-redundant MAGs with minimap v2.17 [73] and relative abundances were calculated as a proportion of the reads mapping to each MAG. 


\section{Results}

\section{Environmental characterization and in situ GHG fluxes}

Our sampling design in Kilpisjärvi included two soil depths across four ecosystems that are characteristic of polar and alpine environments (barren soils, heathlands, meadows, and fens) (Suppl. Figure S1a,b,c). Soil ecosystems differed in vegetation cover and physicochemical composition, with fens in particular being characterized by higher $\mathrm{pH}$, moisture, and $\mathrm{N}$ content (one-way ANOVA, $\mathrm{R}^{2}=0.16-0.64, \mathrm{p}<0.001$ ) and, together with the meadows, lower C:N ratio (one-way ANOVA, $\mathrm{R}^{2}=0.49, \mathrm{p}<0.001$ ) (Suppl. Fig. S1d). In situ measurements of GHG fluxes showed a high sink-source variability in net $\mathrm{N}_{2} \mathrm{O}$ fluxes across the ecosystems (Suppl. Fig. S1e). Although the average $\mathrm{N}_{2} \mathrm{O}$ flux across all sites was small (net consumption of $6 \mu \mathrm{g} \mathrm{N}_{2} \mathrm{O} \mathrm{m}{ }^{-2}$ day $^{-1}$ ), high $\mathrm{N}_{2} \mathrm{O}$ emission at rates of up to $660 \mu \mathrm{g} \mathrm{N}_{2} \mathrm{O} \mathrm{m}$ m $^{-2}$ day $^{-1}$ was observed at

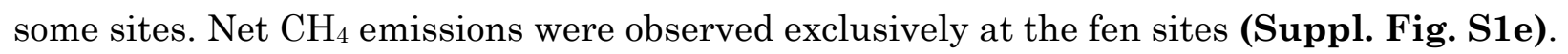

\section{Differences in microbial community structure across soils ecosystems}

We obtained more than 9 billion Illumina (1.4 Tb) and 7 million Nanopore (21.5 Gb) reads from the 69 soil metagenomes (mean: $19.9 \mathrm{~Gb}$, minimum: $0.7 \mathrm{~Gb}$, maximum: $82.9 \mathrm{~Gb}$ ) (Suppl. Table S1). Read-based analyses of unassembled SSU rRNA gene sequences showed that microbial community composition differed across the ecosystems, with fen soils harbouring contrasting microbial communities compared to the other ecosystems (PERMANOVA, $\mathrm{R}^{2}=0.24-0.51$, p < 0.001) (Suppl. Fig. S2a,b). No differences in community structure were observed between soil depths or the interaction between soil ecosystem and depth (PERMANOVA, $p>0.05$ ).

Among previously described (i.e. not unclassified) taxa, microbial communities in barren, heathland, and meadow soils were dominated by aerobic and facultative anaerobic heterotrophs such as Acidobacterium, Actinoallomurus, Conexibacter, Mycobacterium, Bradyrhizobium, Rhodoplanes, Ktedonobacter, Gemmata, and Chthoniobacter (Suppl. Fig. S2c). On the other hand, fen soils were dominated by methanogenic archaea from the genera Methanobacterium and Methanosarcina and anaerobic bacteria such as Geobacter, but also the putative aerobic heterotroph Candidatus Koribacter. Communities from different ecosystems also differed in the abundance of denitrification genes (nirK, nirS, norB, and nosZ), which were more abundant in the meadows and fens (one-way ANOVA, $\mathrm{R}^{2}=0.47-0.72$, p < 0.001) (Suppl. Fig. S2d). Fen soils also had a higher abundance of genes involved in sulfate reduction ( $d s r A$ and $d s r B$ ) and methanogenesis ( $m c r A$ and $m c r B$ ) (one-way ANOVA, $\mathrm{R}^{2}=0.61-0.89, \mathrm{p}<0.001$ ). We did not observe a significant relationship between $\mathrm{N}_{2} \mathrm{O}$ flux rates and neither the abundance of 
bioRxiv preprint doi: https://doi.org/10.1101/2020.12.21.419267; this version posted June 30, 2021. The copyright holder for this preprint (which was not certified by peer review) is the author/funder, who has granted bioRxiv a license to display the preprint in perpetuity. It is made available under aCC-BY-NC-ND 4.0 International license.

individual $\mathrm{N}$ cycle genes nor the ratio between nirK/nirS and nosZ abundances (linear regression, $p>0.05)$.

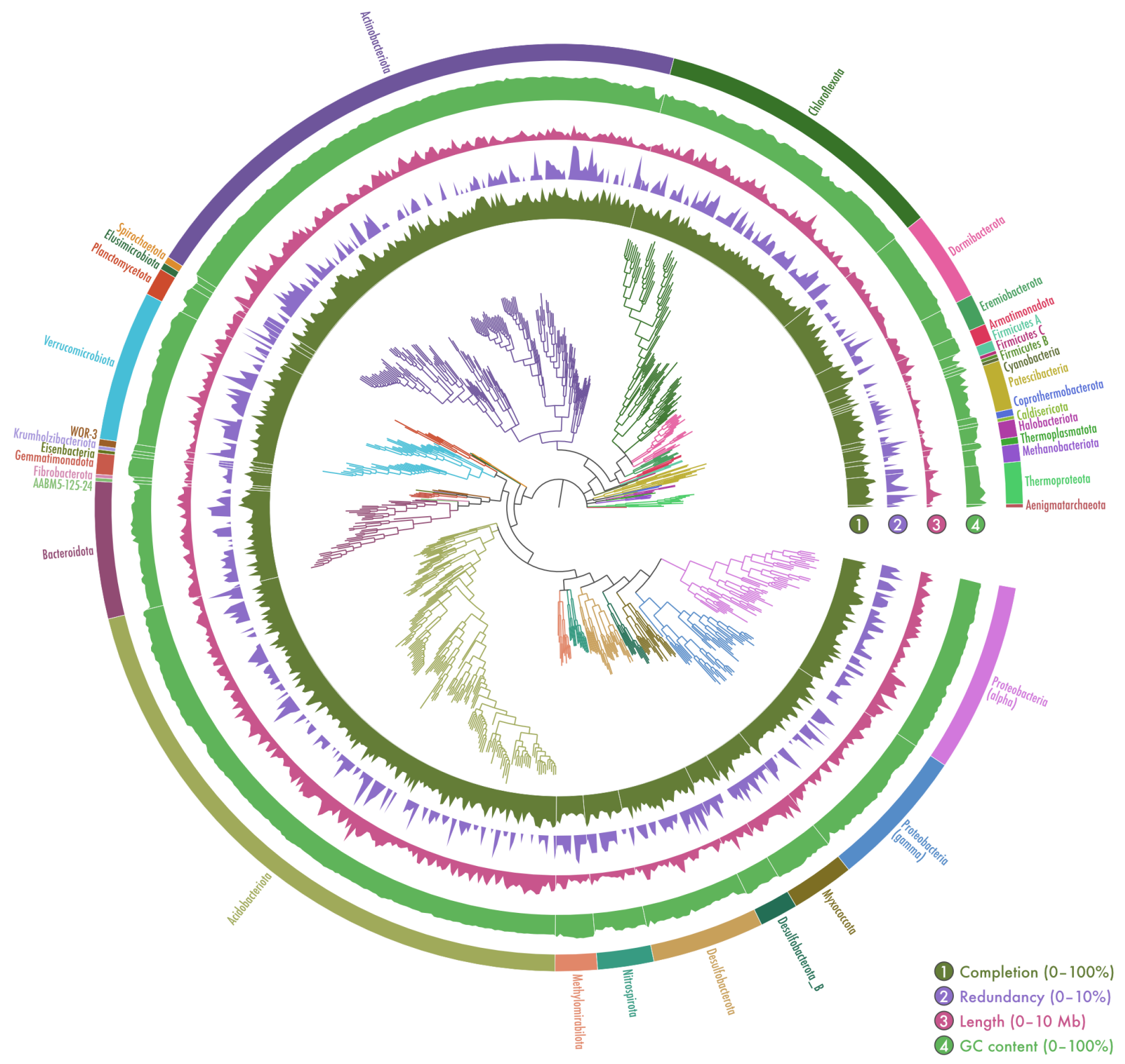

Fig. 1 | Genome-resolved metagenomics of tundra soils. Phylogenomic placement and assembly statistics of 796 metagenome-assembled genomes (MAGs) recovered from soils in Kilpisjärvi, northern Finland. Unrooted maximum likelihood tree based on concatenated alignments of amino acid sequences from 122 archaeal and 120 bacterial single-copy genes. Additional information about the MAGs can be found in Suppl. Table S2. 


\section{A manually curated genomic database from tundra soil metagenomes}

Two Illumina co-assemblies and two individual Nanopore assemblies yielded more than 4 million contigs longer than $2,500 \mathrm{bp}$, with a total assembly size of $21.1 \mathrm{~Gb}$. The co-assemblies covered a significant fraction of the original metagenomic data, with an average read recruitment rate of $54.6 \%$ across samples (minimum: $22.9 \%$, maximum: $75.8 \%$ ). Using anvi'o [55], we obtained 8,043 genomic bins and manually curated these to a set of 796 MAGs that were at least 50\% complete and no more than 10\% redundant (Fig. 1, Suppl. Table S2). According to estimates based on domain-specific single-copy genes, the obtained MAGs were on average $65.4 \%$ complete (minimum: 50.0\%, maximum: $100.0 \%$ ) and $2.7 \%$ redundant (minimum: 0.0\%, maximum: 9.9\%) (Suppl. Table S2). Phylogenomic analyses based on 122 archaeal and 120 bacterial single-copy genes placed the MAGs across 35 bacterial and archaeal phyla according to the GTDB classification [58, 59] (Fig. 1). The most represented phyla were Acidobacteriota $(\mathrm{n}=172)$, Actinobacteriota $(\mathrm{n}=163)$, Proteobacteria (Alphaproteobacteria, $\mathrm{n}=54$; Gammaproteobacteria, $\mathrm{n}=39)$, Chloroflexota $(\mathrm{n}=84)$, and Verrucomicrobiota $(\mathrm{n}=43)$. Most MAGs $(n=703)$ belonged to genera that do not comprise formally described species, including 303 MAGs that were placed outside genus-level lineages currently described in GTDB and thus likely represent novel genera (Suppl. Table S2).

To investigate their distribution across the different soil ecosystems, MAGs were dereplicated based on a 90\% ANI threshold, yielding a set of 761 non-redundant MAGs (Fig. 2). On average, $15.8 \%$ of the reads from each sample were recruited by the set of non-redundant MAGs (minimum: 7.6\%, maximum: 30.5\%). In agreement with the read-based assessment, we observed differences in MAG composition across the soil ecosystems, with only 50 MAGs shared between the heathland, meadow, and fen soils (Suppl. Fig. S3a). Fen soils harboured the highest number of MAGs, with an average of 155 MAGs per sample (Suppl. Fig. S3b). Although barren and fen soils had similar taxonomic richness according to the read-based estimates, only a small number of MAGs was detected in the barren soils (average of four MAGs per sample). This is likely a result of limited sampling and sequencing of this ecosystem, which consisted of four samples and a total of $7.9 \mathrm{~Gb}$ of metagenomic data (Suppl. Table S1). The number of MAGs in heathland and meadow soils was similar (average of 47 and 63 MAGs per sample, respectively) (Suppl. Fig. S3b). In general, barren, heathland, and meadow soils were dominated by the same set of MAGs (Suppl. Fig. S3c). These included members of the Acidobacteriota (Sulfotelmatobacter and unclassified genera in the class Acidobacteriae), Actinobacteriota (Mycobacterium and unclassified genera in the family Streptosporangiaceae), and Proteobacteria (Alphaproteobacteria: Reyranella, Bradyrhizobium, and unclassified 
Xanthobacteraceae; Gammaproteobacteria: unclassified Steroidobacteraceae). On the other hand, fen soils were dominated by MAGs that were not assigned to formally described genera, including lineages of Acidobacteriota (family Koribacteraceae), Actinobacteriota (family Solirubrobacteraceae), Chloroflexota (class Ellin6529), Desulfobacterota (order Desulfobaccales), and Halobacterota.

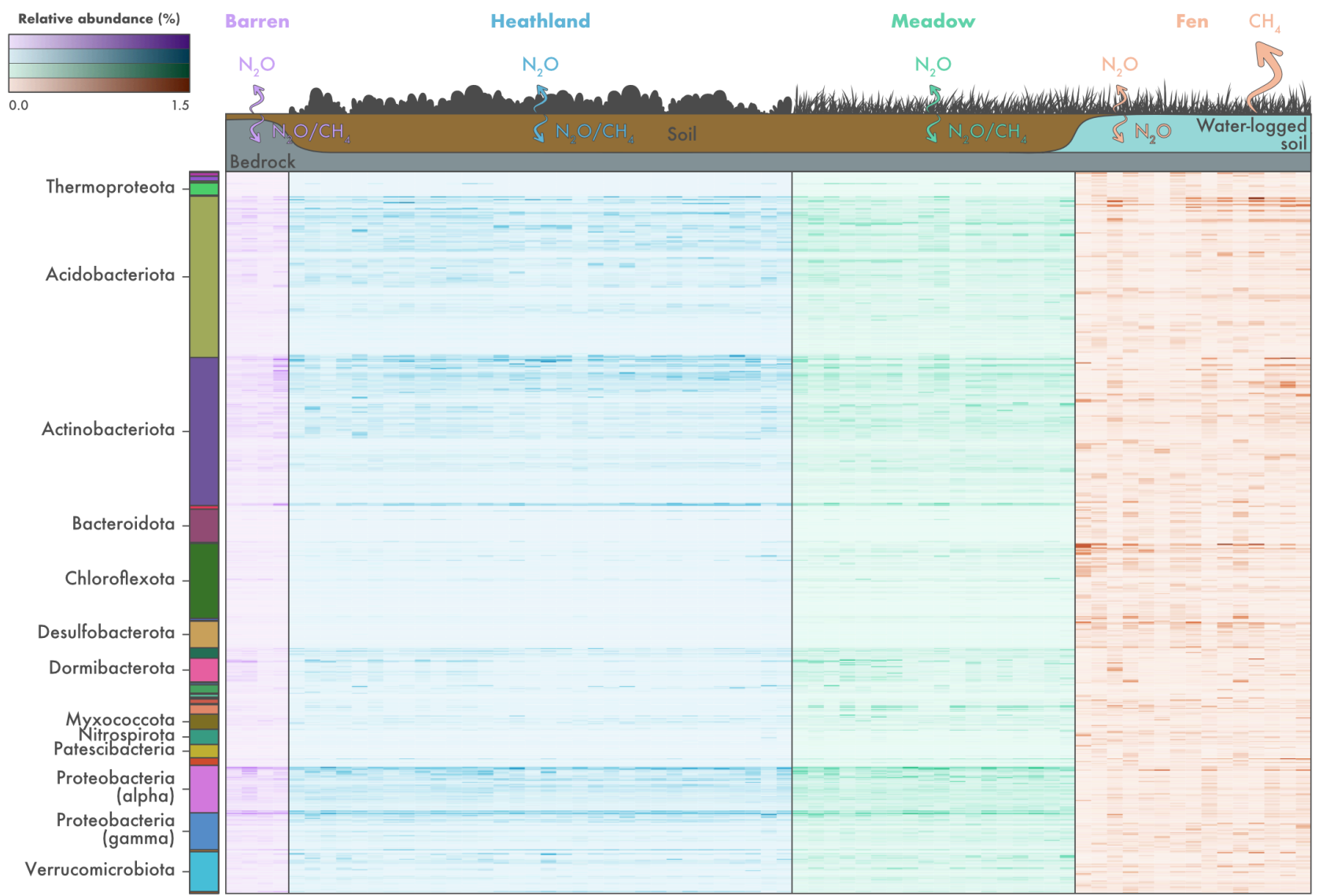

Fig. 2 | Microbial community composition across different soil ecosystems in the tundra. Relative abundance of 761 non-redundant metagenome-assembled genomes (MAGs) recovered from soils in Kilpisjärvi, northern Finland. Relative abundances were computed as a proportion of the reads mapping to each MAG. Phylum-level taxonomic assignments are shown for the major groups found. The scheme on the top of the figure represents ecosystem-level methane $\left(\mathrm{CH}_{4}\right)$ and nitrous oxide $\left(\mathrm{N}_{2} \mathrm{O}\right)$ fluxes based on in situ measurements (Suppl. Fig. S1).

\section{Microorganisms from tundra soils have truncated denitrification pathways}

To gain insights into the microorganisms involved with the cycling of $\mathrm{N}_{2} \mathrm{O}$ in tundra soils, we searched the MAGs for genes involved in denitrification, a key process controlling $\mathrm{N}_{2} \mathrm{O}$ production in soils [11]. We focused on the nirK/nirS, norB, and nosZ genes which encode the nitrite (Nir), nitric oxide (Nor), and nitrous oxide (Nos) reductases, respectively [12]. Gene 
annotation was performed using a three-step approach to avoid false positives consisting of distantly related homologues that are not involved in denitrification. Putative genes were first identified by searching predicted amino acid sequences against curated HMMs from the KOfam database [64]. Positive matches were then aligned and manually inspected for the presence of conserved residues at specific positions associated with the binding of co-factors and active sites [66-68]. Sequences containing the correct amino acid at these core positions were further submitted to phylogenetic analyses along with sequences from a comprehensive database of archaeal and bacterial genomes [14] (Suppl. Fig. S4, Suppl. Fig. S5, Suppl. Fig. S6, Suppl. Fig. S7).

We identified denitrification genes in 110 of the 796 MAGs (13.8\%) (Suppl. Table S2). These were affiliated with the archaeal phylum Thermoproteota and many bacterial phyla such as Proteobacteria (Gamma- and Alphaproteobacteria), Acidobacteriota, Bacteroidota, Actinobacteriota, Chloroflexota, and Verrucomicrobiota (Fig. 3a). However, only 17 MAGs were assigned to a validly described genera (Suppl. Table S2). These included members of the Acidobacteriota (Solibacter, Sulfotelmatobacter, Terracidiphilus, and Gaiella), Myxococcota (Anaeromyxobacter), Planctomycetota (Singulisphaera), Proteobacteria (Alphaproteobacteria: Bauldia, Bradyrhizobium, Methylocella, and Reyranella; Gammaproteobacteria: Gallionella and Rhizobacter), and Verrucomicrobiota (Lacunisphaera and Opitutus). On average, 1.8\% of the reads in each sample were recruited by all denitrifiers combined (minimum: 0.4\%, maximum: $6.1 \%)$. In general, denitrifiers were most abundant in the fens (1.0-6.1\%) and least abundant in the heathlands (0.4-2.1\%). When taking into account only reads mapping to the 796 MAGs, denitrifiers represented on average $11.1 \%$ of the reads in each sample (minimum: 3.0\%, maximum: 26.8\%).

Genes involved in denitrification were found exclusively in MAGs with truncated denitrification pathways, i.e. MAGs missing one or more genes involved in the complete denitrification process (Fig. 3a). Of the 110 MAGs harbouring denitrification genes, the vast majority ( $=104)$ encoded only one of the Nir, Nor, and Nos enzymes and no MAG encoded all the three enzymes required for the reduction of $\mathrm{NO}_{2}-$ to $\mathrm{N}_{2}$. Unsurprisingly, co-occurrence of genes encoding the three enzymes was also not observed in any of the other genomic bins of lower quality that were discarded from the final MAG dataset (i.e. bins that were $<50 \%$ complete and/or $>10 \%$ redundant). To verify if microorganisms with truncated denitrification pathways are common in other tundra systems, we expanded our analysis to 1529 MAGs recovered from permafrost peatland, bog, and fen soils in Stordalen Mire, northern Sweden [28]. Among these, 225 MAGs (14.7\%) contained denitrification genes (Suppl. Fig. S8). MAGs encompassed a similar taxonomic profile as observed in the Kilpisjärvi dataset, and MAGs with truncated 
denitrification pathways were also the norm in Stordalen Mire soils. Only one MAG, assigned to the Gammaproteobacteria genus Janthinobacterium, encoded all the Nir, Nor, and Nos enzymes required for the reduction of $\mathrm{NO}_{2}{ }^{-}$to $\mathrm{N}_{2}$.

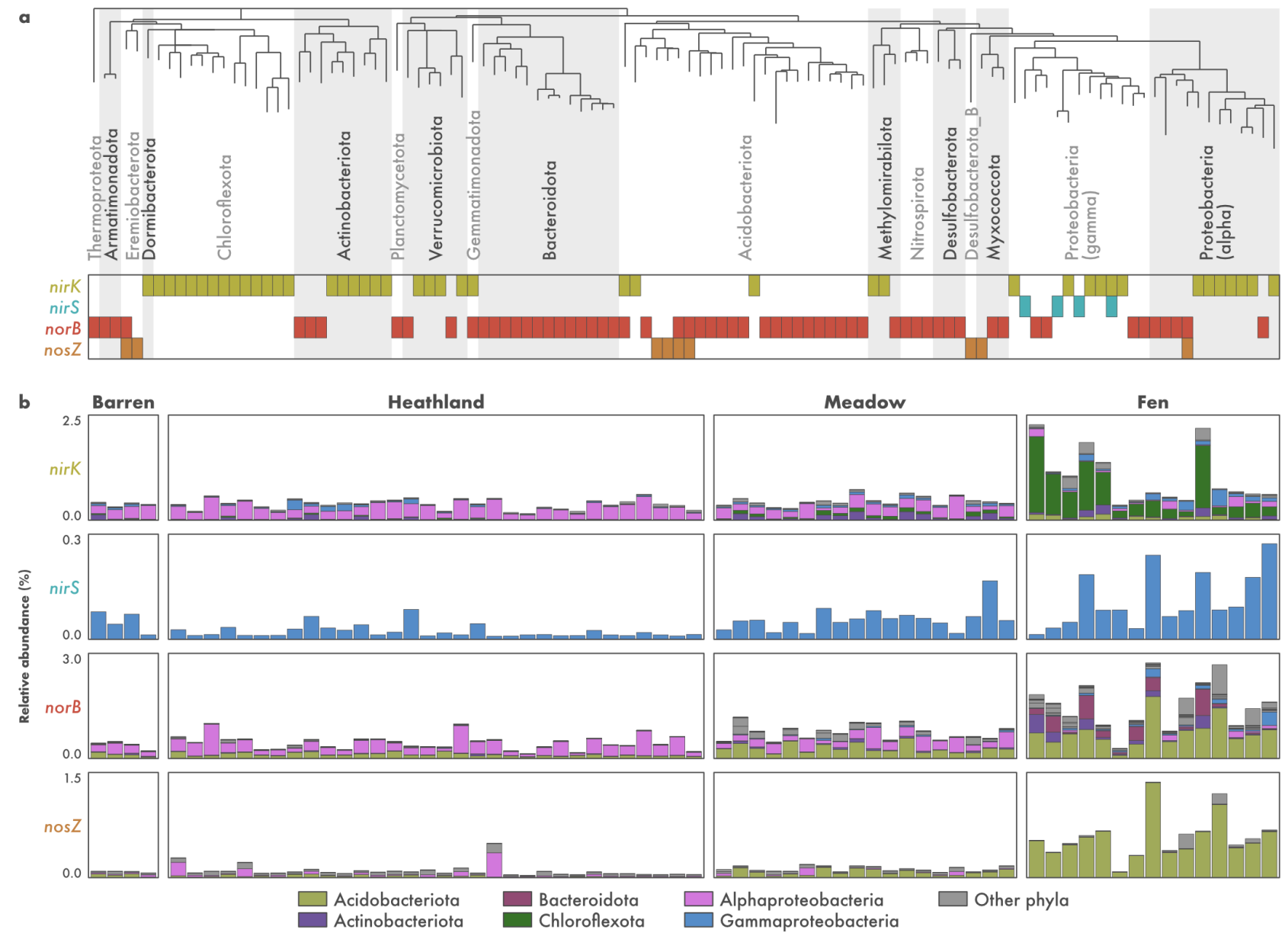

Fig. 3| Metabolic potential for denitrification in tundra soils. a) Distribution of denitrification genes across 110 metagenome-assembled genomes (MAGs) recovered from tundra soils in Kilpisjärvi, northern Finland. Genes encoding the nitrite (nirK/nirS), nitric oxide (nor $B)$, and nitrous oxide (nos $Z$ ) reductases were annotated using a three-step approach including (1) identification using hidden Markov models from the KOfam database, (2) manual inspection for the presence of conserved residues at positions associated with the binding of cofactors and active sites, and (3) phylogenetic analyses along with sequences from archaeal and bacterial genomes (Suppl. Fig. S4-S7). b) Phylum-level relative abundance of microorganisms harbouring denitrification genes across the different soil ecosystems, computed as a proportion of reads mapping to each MAG. 


\section{Microorganisms affiliated with the Chloroflexota lineage Ellin6529 are the main denitrifiers stricto sensu in fen soils}

The reduction of $\mathrm{NO}_{2}-$ to $\mathrm{NO}$, performed by microorganisms harbouring the nirK or nirS genes, is the hallmark step of denitrification and is often referred to as denitrification stricto sensu as it involves the conversion of a soluble substrate to a gaseous product thus leading to the removal of $\mathrm{N}$ from the system [12]. Within the 110 Kilpisjärvi MAGs harbouring genes involved in denitrification, 46 contained nirK/nirS genes and are thus potential denitrifiers stricto sensu (Fig. 3a). These belonged mainly to the bacterial phyla Chloroflexota, Actinobacteriota, and Proteobacteria (Alpha- and Gammaproteobacteria). Most MAGs ( $\mathrm{n}=43$ ) contained the nirK gene, which encodes the copper-containing form of Nir (Suppl. Fig. S4). The nirS gene encoding the cytochrome $\mathrm{cd}_{1}$-containing form of Nir was present in four Gammaproteobacteria MAGs (Suppl. Fig. S5), including one MAG that contained both genes.

The composition of potential denitrifier stricto sensu communities differed across the ecosystems (Fig. 3b). MAGs belonging to the Alphaproteobacteria class of the Proteobacteria were the most abundant in the barren, heathland, and meadow soils, particularly the MAG KUL-0154 assigned to the genera Bradyrhizobium (Suppl. Fig. S9). Two other Alphaproteobacteria MAGs that do not correspond to formally described genera in the families Acetobacteraceae and Beijerinckiaceae (KUL-0057 and KUL-0056, respectively) were also found at lower relative abundances. In addition, one Actinobacteriota MAG assigned to an uncharacterized genus in the family Gaiellaceae (KWL-0073), was abundant in the meadow soils. On the other hand, fen communities were dominated by MAGs belonging to the phylum Chloroflexota (Fig. 3b), which included seven MAGs assigned to the class-level lineage Ellin6529 (Suppl. Fig. S9).

None of the Ellin6529 MAGs contained the key genes involved in autotrophic carbon fixation, dissimilatory sulfate reduction, dissimilatory nitrate reduction to ammonia, and nitrogen fixation (Suppl. Table S3). Analysis of genes encoding terminal oxidases involved in the aerobic respiratory electron chain revealed that all seven Ellin6529 MAGs harboured the cox $A B C$ genes encoding the aa3-type cytochrome c oxidase. Four MAGs also contained the $\operatorname{cyd} A B$ genes encoding the cytochrome bd ubiquinol oxidase, a terminal oxidase with high affinity for oxygen that also plays a role in protecting against harmful conditions such as oxidative and nitrosative stress [74, 75]. The dominant MAGs in the barren, heathland, and meadow soils contained a different set of genes encoding aerobic terminal oxidases. In addition to the $c y d A B$ genes, the MAGs KUL-0057 and KUL-0154 also contained the $c y o A B C D$ genes encoding the cytochrome o ubiquinol oxidase, which is the main terminal oxidase under highly aerobic conditions [76], and KUL-0057 also contained genes encoding the $c b b 3$-type cytochrome 
c oxidase, a terminal oxidase with high affinity for oxygen [77]. Genes involved in the Calvin cycle (e.g. rbcL, rbcS, and prkB) were found in the Bradyrhizobium MAG (KUL-0154), and none of the key genes for autotrophic carbon fixation pathways were present in the other dominant Alphaproteobacteria MAGs.

\section{Acidobacteriota with the potential to reduce $\mathrm{NO}$ and $\mathrm{N}_{2} \mathrm{O}$ are abundant in the fens}

The stepwise reduction of $\mathrm{NO}$ to $\mathrm{N}_{2} \mathrm{O}$ and $\mathrm{N}_{2}$ carried out by microorganisms containing the nor $B$ and nos $Z$ genes, respectively, represents the final step of denitrification and the main biotic control on $\mathrm{N}_{2} \mathrm{O}$ emissions. Soil denitrification rates depend on multiple environmental conditions such as adequate moisture and inorganic $\mathrm{N}$ availability, but whether it results in the emission of $\mathrm{N}_{2} \mathrm{O}$ or $\mathrm{N}_{2}$ is ultimately linked to a balance between the activity of $\mathrm{NO}$ and $\mathrm{N}_{2} \mathrm{O}$ reducers $[11,15]$. The nor $B$ and $\operatorname{nos} Z$ genes were identified in 62 and 9 Kilpisjärvi MAGs, respectively, belonging mostly to the phyla Actinobacteriota, Bacteroidota, Acidobacteriota, and Proteobacteria (class Alphaproteobacteria) (Fig. 3a). With the exception of one Gemmatimonadota and one Acidobacteriota MAG, norB- and nosZ-containing MAGs were almost exclusively non-denitrifiers stricto sensu, i.e. they did not harboured the nirK/nirS genes involved in the reduction of $\mathrm{NO}_{2}{ }^{-}$to NO. Most MAGs $(\mathrm{n}=48)$ harboured a norB gene encoding the monomeric, quinol-dependent form of Nor ( $q$ Nor), while the remaining MAGs $(n=8)$ encoded the cytochrome c-dependent Nor (cNor) (Suppl. Fig. S6). In regards to the nos $Z$ gene, most MAGs $(n=6)$ contained sequences affiliated with the cluster II (also known as atypical) NosZ [14, 15, 78] (Suppl. Fig. S7). Only four MAGs contained both the norB and nosZ genes and thus have the potential to reduce NO completely to $\mathrm{N}_{2}$ (Fig. 3a).

As observed for the denitrifier stricto sensu communities, the communities of potential NO and $\mathrm{N}_{2} \mathrm{O}$ reducers also differed between the ecosystems (Fig. 3b). MAGs assigned to the Alphaproteobacteria class of the Proteobacteria were the most abundant in the barren, heathland, and meadow soils. In particular, the MAG KWL-0112 assigned to the genera Reyranella was the dominant norB-containing MAG, while KUL-0116 (belonging to an uncharacterized genus in the family Acetobacteraceae) was the dominant MAG harbouring the nosZ gene (Suppl. Fig. S9). On the other hand, fen communities were dominated by Acidobacteriota MAGs (Fig. 3b), particularly the norB- and nosZ-containing MAG KWL-0326 affiliated with the class Thermoanaerobaculia (Suppl. Fig. S9). This MAG contained the same set of genes encoding aerobic terminal oxidases as found in the nirK-containing Ellin6529 MAGs that were dominant in the fen sites, namely $\operatorname{cox} A B C$ and $c y d A B$ (Suppl. Table S3). Likewise, the two MAGs that were dominant in the barren, heathland, and meadow soils (KWL-0112 and KUL-0116) contained genes encoding the $c b b 3$-type cytochrome c oxidase, which was also found 
in one of the dominants nirK-containing Alphaproteobacteria MAG. No genes involved in carbon fixation, dissimilatory sulfate reduction, dissimilatory nitrate reduction to ammonia, and nitrogen fixation were found in any of the dominant nor $B$ - and nosZ-containing MAGs.

To elucidate the phylogenetic placement of the Acidobacteriota MAGs and to verify if the potential for $\mathrm{NO}$ and $\mathrm{N}_{2} \mathrm{O}$ reduction is present in other members of this phylum, we included in our analysis all available genomes of Acidobacteriota strains and candidate taxa available on GenBank. This revealed that genes encoding the Nir and Nos enzymes are widespread across the phylum Acidobacteriota (Fig. 4). Genes encoding the Nor enzyme were present in all but one of the six Acidobacteriota subdivisions with genomes from cultured representatives. This included the strains Acidobacterium ailaaui PMMR2 (subdivision Gp1), Acidipila sp. 4G-K13 (Gp1), Silvibacterium bohemicum DSM 103733 and S. bohemicum S15 (Gp1), Acidobacteriaceae bacterium URHE0068 (Gp1), Edaphobacter aggregans DSM 19364 (Gp1), Luteitalea pratensis DSM 100886 (Gp6), Geothrix fermentans DSM 14018 (Gp8), and Thermoanaerobaculum aquaticum MP-01 (Gp23), as well as the candidate taxa Candidatus Koribacter versatilis Ellin345 (Gp1), Candidatus Sulfotelmatomonas gaucii SbA5 (Gp1), and Candidatus Solibacter usitatus Ellin6076 (Gp3). On the other hand, genes encoding the Nos enzyme were found only in members of the subdivisions Gp6 and Gp23.

\section{Discussion}

The 796 MAGs obtained in the present study by a manual binning and curation effort represent one of the largest genomic catalogues of microorganisms from tundra soils to date. Earlier genecentric investigations have demonstrated the potential for complete denitrification in tundra soils [22, 79], however, these approaches fail to reveal the wider genomic context of the genes. By applying the genome-resolved metagenomics approach, we traced denitrification genes to specific microbial populations, thereby allowing a detailed investigation of the genomic makeup of potential denitrifiers in tundra soils. This approach also enabled us to access the genomes of uncultured, poorly characterized taxa, which comprise the majority of the microorganisms in soils and other complex ecosystems [24, 25]. Our genome-resolved survey revealed that denitrification in tundra soils is dominated by microorganisms with truncated denitrification pathways, most of which represent poorly characterized taxa without cultured representatives. With the support of in situ measurements of $\mathrm{N}_{2} \mathrm{O}$ fluxes, we hypothesize that microorganisms with truncated denitrification pathways are the main drivers of $\mathrm{N}_{2} \mathrm{O}$ cycling in tundra soils. 
bioRxiv preprint doi: https://doi.org/10.1101/2020.12.21.419267; this version posted June 30, 2021. The copyright holder for this preprint (which was not certified by peer review) is the author/funder, who has granted bioRxiv a license to display the preprint in perpetuity. It is made available under aCC-BY-NC-ND 4.0 International license.

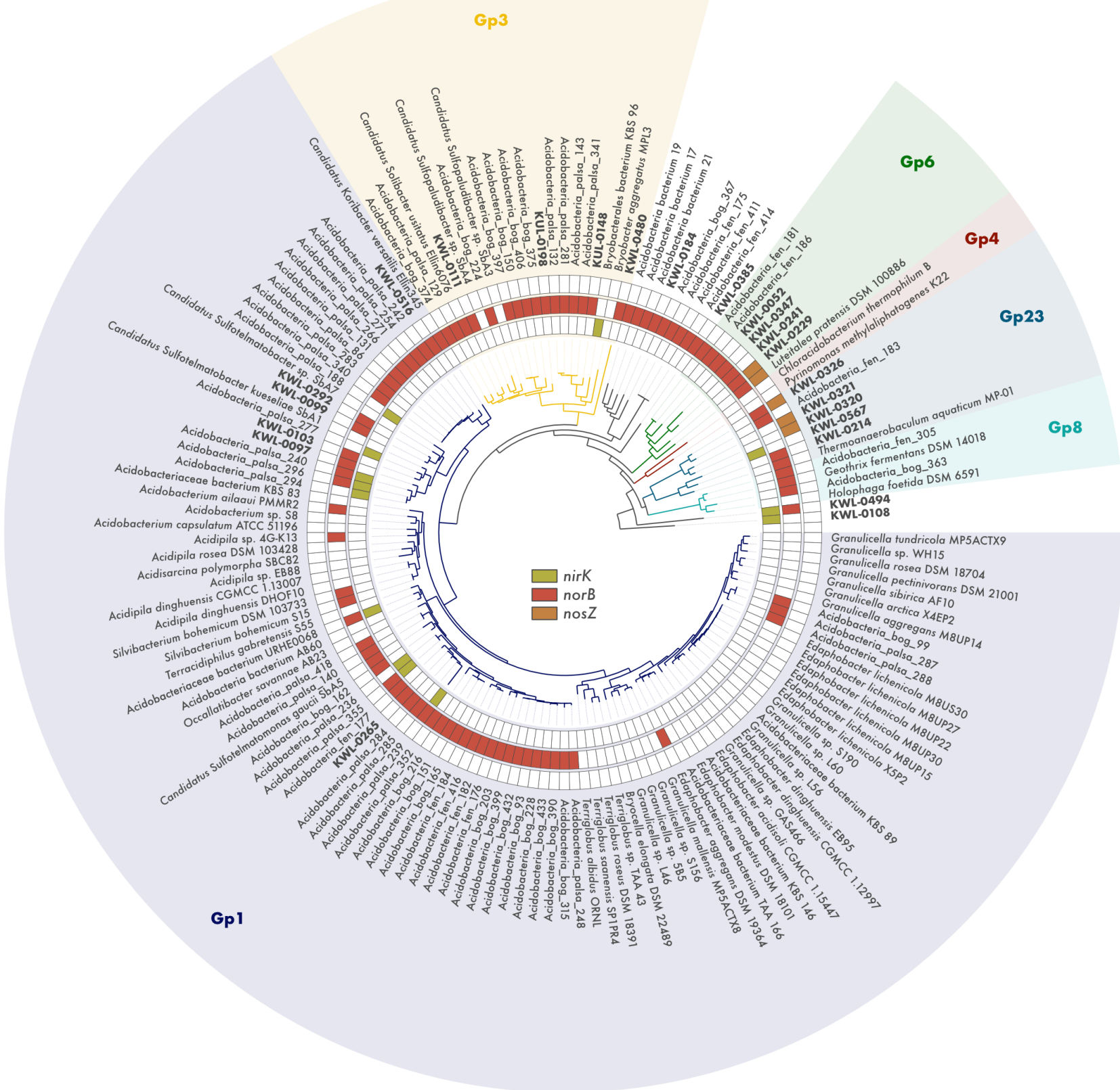

\section{Fig. 4 | Metabolic potential for denitrification among members of the phylum} Acidobacteriota. Phylogenomic analysis of 85 Acidobacteriota metagenome-assembled genomes (MAGs) containing denitrification genes recovered from tundra soils in Kilpisjärvi (northern Finland) and Stordalen Mire (northern Sweden), and 69 genomes of Acidobacteriota strains and candidate taxa. Maximum likelihood tree based on concatenated alignments of 23 ribosomal proteins and rooted with Escherichia coli ATCC 11775 (not shown). Genes encoding the nitrite (nirK), nitric oxide (norB), and nitrous oxide (nosZ) reductases were annotated using a three-step approach to avoid false positives (see methods). 
The congruence of these findings in both our original analysis of northern Finland soils and our re-analysis of a comprehensive metagenomic dataset from soils in northern Sweden [28] suggests that truncated denitrification pathways are not a methodological artifact arising from the metabolic reconstruction of fragmented genomes. Indeed, recent genome-resolved investigations have shown that truncated metabolic pathways, also known as metabolic handoffs, are the norm across a wide range of ecosystems such as grassland soil, aquifer sediment, groundwater, and the ocean, and not only in relation to denitrification but other redox transformations as well [80-82]. Although denitrification has traditionally been known as a community effort performed by different microbial populations [12-15], these genome-resolved metagenomic studies are beginning to reveal a more in-depth, ecosystem-centric representation of the denitrification pathway. In addition to their predominance in genomic databases [14], it appears that truncated denitrifiers are dominant within defined ecosystems across various terrestrial and aquatic biomes, including the tundra. It has been suggested that the partitioning of metabolic pathways across different populations via metabolic handoffs is advantageous as it eliminates competition between enzymes accelerating substrate consumption [15, 83] and provides flexibility and resilience to the communities in face of environmental disturbances [80]. We further hypothesize that the predominance of denitrification pathways characterized mostly by metabolic handoffs in tundra soils could be related to $\mathrm{N}$ limitation. If metabolic handoffs enable a more effective substrate consumption as previously suggested [15, 83], truncated denitrification pathways would be favoured in tundra soils which are mostly $\mathrm{N}$ limited but undergo rapid surges in $\mathrm{N}$ availability e.g. during the spring melting season [84].

Our results showed that tundra microbial communities differ between dryer upland ecosystems (barren, heathland, and meadow soils) and the water-logged fens. This is likely explained by large differences in soil moisture, which further affects oxygen availability in these ecosystems. The dominant denitrifier populations in the mostly oxic dry upland soils, related to the genera Bradyrhizobium, Reyranella, and other uncharacterized genera in the class Alphaproteobacteria, encode aerobic terminal oxidases that are active under highly aerobic conditions as well as oxidases with high oxygen affinity $[76,77]$. This likely provides an adaptive advantage in these soils by allowing rapid aerobic growth under standard conditions of high oxygen availability as well as sustaining growth in microoxic niches within the soil matrix and during periods of reduced oxygen availability (e.g. during the spring melting season). On the other hand, fen soils are continuously inundated because the water table is at or near the soil surface. The result is a mostly anoxic environment due to the slow rate at which oxygen diffuses into the water-logged soil, favouring reduced rather than oxidized soil chemistry. In line with this, we found a predominance of anaerobic processes in the fens, including a higher abundance 
of genes involved in denitrification, sulfate reduction, and methanogenesis, the latter supported by in situ observations of net $\mathrm{CH}_{4}$ emission. Interestingly, the dominant populations in the fen soils, assigned to the Chloroflexota lineage Ellin6529 and the subdivision Gp23 of the Acidobacteriota, encode the cytochrome $b d$ oxidase which plays a role in preventing the inactivation of oxygen-sensitive enzymes and protecting against oxidative and nitrosative stress, toxic compounds such as cyanide, and other stress conditions such as high temperature and high $\mathrm{pH}[74,75]$. This cytochrome also has a high oxygen affinity, thus likely enabling these microorganisms to grow aerobically later in the growing season when fen soils are drier and thus less anoxic.

An interesting finding was that the communities of potential denitrifiers in the fen soils were dominated by somewhat enigmatic taxa, namely potential $\mathrm{NO}_{2}{ }^{-}$reducers affiliated with the class Ellin6529 of the Chloroflexota and $\mathrm{NO} / \mathrm{N}_{2} \mathrm{O}$ reducers assigned to the subdivision Gp23 of the Acidobacteriota. Both groups are major members of microbial communities in soils worldwide [85], and RNA-based investigations have shown that they are active in tundra soils during both summer and winter seasons [32, 86]. Ellin6529 - formerly G04 - were first detected by culture-independent methods in alpine tundra wet meadow soil in the Colorado Rocky Mountains, USA [87], and later isolated in a study targeting slow-growing and mini-colony forming bacteria from Australian agricultural soil [88]. However, their ecological, physiological, and metabolic preferences remain largely unknown. Thermoanaerobaculum aquaticum MP-01, the only cultivated member of the Acidobacteriota subdivision Gp23, is a strictly anaerobic bacterium that has been shown to use $\mathrm{Fe}$ and $\mathrm{Mn}$, but not $\mathrm{NO}_{3}{ }^{-}$nor $\mathrm{NO}_{2}{ }^{-}$, as electron acceptors in anaerobic respiration [89]. However, studies investigating the use of nitrogen oxides in anaerobic respiration usually provide soluble $\mathrm{NO}_{3}{ }^{-}$or $\mathrm{NO}_{2}{ }^{-}$as electron acceptors, not the gases $\mathrm{NO}$ and $\mathrm{N}_{2} \mathrm{O}$, which bias against truncated denitrifiers that do not contain the narG and nirK/nirS genes [90]. Their high abundance in the water-logged, anoxic fen soils suggest that the Ellin6529 and Gp23 populations found in this study are able to grow anaerobically with the use of $\mathrm{NO}$ and $\mathrm{N}_{2} \mathrm{O}$ as electron acceptors. However, it is known that in addition to their role in anaerobic respiration, $\mathrm{NO}$ and $\mathrm{N}_{2} \mathrm{O}$ reduction can be used as a detoxification mechanism or even as electron sink for metabolism. For example, the aerobe Gemmatimonas aurantica T-27 is not able to grow on $\mathrm{N}_{2} \mathrm{O}$ alone, but instead uses $\mathrm{N}_{2} \mathrm{O}$ as electron acceptor transiently when oxygen is depleted [91].

Despite differences in community structure, our results showed that both meadows and fens are potential denitrification hotspots, with a higher abundance of denitrification genes than barren and heathland soils. In addition, the low $\mathrm{C}: \mathrm{N}$ ratio in the meadow and fen soils might indicate higher rates of $\mathrm{N}$ mineralization and thus high $\mathrm{N}$ bioavailability, likely supporting 
denitrification in these ecosystems [4, 92]. The largely anoxic conditions, high $\mathrm{pH}$ and SOM content in fen soils, in particular, make them important sources of $\mathrm{N}_{2} \mathrm{O}$ in the tundra [7]. Although the in situ $\mathrm{N}_{2} \mathrm{O}$ fluxes measured in this study were highly variable across ecosystems, most fen sites represented $\mathrm{N}_{2} \mathrm{O}$ sources, and $\mathrm{N}_{2} \mathrm{O}$ sinks in the fens were of smaller magnitude compared to meadows and heathlands. However, no direct links could be observed between denitrifier community composition and in situ $\mathrm{N}_{2} \mathrm{O}$ fluxes. Indeed, modelling $\mathrm{N}_{2} \mathrm{O}$ emissions based on microbial community structure is challenging, as $\mathrm{N}_{2} \mathrm{O}$ fluxes are characterized by a high temporal and spatial variability driven by several environmental constraints related to soil $\mathrm{pH}, \mathrm{N}$, moisture, and oxygen content [11]. Studies have suggested that incomplete denitrifiers that contain Nir and Nor but lack Nos (thus having $\mathrm{N}_{2} \mathrm{O}$ as the end product of denitrification) can contribute substantially to soil $\mathrm{N}_{2} \mathrm{O}$ emissions [93]. At the same time, non-denitrifying $\mathrm{N}_{2} \mathrm{O}$ reducers, i.e. microorganisms that contain Nos but lack Nir, can represent an important $\mathrm{N}_{2} \mathrm{O}$ sink [78, 94, 95]. However, while microorganisms with truncated denitrification pathways appear to dominate the denitrifier communities investigated here and elsewhere [80-82], the potential for complete denitrification is present at the ecosystem level. Our current knowledge of the regulation of the denitrification process is largely based on the activity of model organisms such as the complete denitrifier Paracoccus denitrificans [96], and so it remains unclear how a community dominated by truncated denitrifiers interacts with each other and the environment and impact $\mathrm{N}_{2} \mathrm{O}$ emissions in situ.

\section{Conclusions}

A better understanding of denitrification is paramount for our ability to model $\mathrm{N}_{2} \mathrm{O}$ emissions and mitigate climate change [23, 96]. High-latitude environments in particular have experienced amplified warming in recent decades, a trend that is likely to continue in the coming centuries [10]. As mechanisms of GHG emissions are very climate sensitive, the contribution of tundra soils to global GHG atmospheric levels is thus predicted to increase in the future leading to a positive feedback loop [8,9]. Compared with carbon dioxide and $\mathrm{CH}_{4}$, measurements of $\mathrm{N}_{2} \mathrm{O}$ fluxes in tundra soils are sparse and are rarely coupled with a characterization of the microorganisms involved, making the magnitude and drivers of $\mathrm{N}_{2} \mathrm{O}$ fluxes across the polar regions uncertain [7]. In addition to a better monitoring of $\mathrm{N}_{2} \mathrm{O}$ emissions throughout the tundra biome, our results suggest that a better understanding of the contribution of tundra soil to global $\mathrm{N}_{2} \mathrm{O}$ levels relies on the elucidation of the regulatory mechanisms of metabolic handoffs in communities dominated by truncated denitrifiers. 


\section{Data availability}

Raw metagenomic data and assembled MAGs have been submitted to the European Nucleotide Archive (ENA) under the project PRJEB41762.

\section{Code availability}

All the code used can be found in https://github.com/ArcticMicrobialEcology/Kilpisjarvi-MAGs.

\section{Acknowledgements}

This work was funded by the Academy of Finland (grants 314114 and 335354) and the University of Helsinki. SV was funded by the Microbiology and Biotechnology Doctoral Programme (MBDP). AMV was funded by the Academy of Finland (grant 286950), the Otto Malm Foundation, and the Gordon and Betty Moore Foundation (grant 8414). MEM was supported by the Academy of Finland (grants 314630 and 317054). We would like to acknowledge CSC - IT Centre for Science for providing the requisite computing resources and Kimmo Mattila for IT support; the staff from the Kilpisjärvi Biological Station, Tanja Orpana, Aino Rutanen, Anniina Sarekoski, Johanna Kerttula, and the members of the BioGeoClimate Modelling Lab for assistance with fieldwork and soil characterization; Jillian Banfield and Christina Biasi for helpful discussion; Laura Cappelatti for proof-reading the manuscript; and Murat Eren, Sebastian Lücker, Donovan Parks, and Antonios Kioukis for tips, recommendations, and troubleshooting.

\section{Author contributions}

$\mathrm{JH}$ and $\mathrm{ML}$ designed the research; SV and $\mathrm{JH}$ performed nucleic acid extraction and metagenomic library preparation; AMV and MEM designed and performed the GHG flux measurements and analyses; ISP analysed the data and wrote the manuscript; EER and TOD contributed with the analyses; all authors contributed to the final version of the manuscript.

\section{Competing interests}

The authors declare no competing interests. 


\section{References}

1. IPCC (ed). Climate Change 2013: The Physical Science Basis. Contribution of Working Group I to the Fifth Assessment Report of the Intergovernmental Panel on Climate Change. 2013. Cambridge University Press, Cambridge.

2. Tian H, Xu R, Canadell JG, Thompson RL, Winiwarter W, Suntharalingam P, et al. A comprehensive quantification of global nitrous oxide sources and sinks. Nature 2020; 586: 248-256.

3. Repo ME, Susiluoto S, Lind SE, Jokinen S, Elsakov V, Biasi C, et al. Large $\mathrm{N}_{2} \mathrm{O}$ emissions from cryoturbated peat soil in tundra. Nat Geosci 2009; 2: 189-192.

4. Marushchak ME, Pitkämäki A, Koponen H, Biasi C, Seppälä M, Martikainen PJ. Hot spots for nitrous oxide emissions found in different types of permafrost peatlands. Glob Change Biol 2011; 17: 2601-2614.

5. Stewart KJ, Grogan P, Coxson DS, Siciliano SD. Topography as a key factor driving atmospheric nitrogen exchanges in arctic terrestrial ecosystems. Soil Biol Biochem 2014; 70: 96-112.

6. Voigt C, Marushchak ME, Lamprecht RE, Jackowicz-Korczyński M, Lindgren A, Mastepanov M, et al. Increased nitrous oxide emissions from Arctic peatlands after permafrost thaw. Proc Natl Acad Sci 2017; 114: 6238-6243.

7. Voigt C, Marushchak ME, Abbott BW, Biasi C, Elberling B, Siciliano SD, et al. Nitrous oxide emissions from permafrost-affected soils. Nat Rev Earth Environ 2020; 1: 420-434.

8. Schuur EAG, McGuire AD, Schädel C, Grosse G, Harden JW, Hayes DJ, et al. Climate change and the permafrost carbon feedback. Nature 2015; 520: 171-179.

9. Hugelius G, Loisel J, Chadburn S, Jackson RB, Jones M, MacDonald G, et al. Large stocks of peatland carbon and nitrogen are vulnerable to permafrost thaw. Proc Natl Acad Sci 2020; 117: 20438-20446.

10. Post E, Alley RB, Christensen TR, Macias-Fauria M, Forbes BC, Gooseff MN, et al. The polar regions in a $2^{\circ} \mathrm{C}$ warmer world. Sci Adv 2019; 5: eaaw9883.

11. Butterbach-Bahl K, Baggs EM, Dannenmann M, Kiese R, Zechmeister-Boltenstern S. Nitrous oxide emissions from soils: how well do we understand the processes and their controls? Philos Trans R Soc B Biol Sci 2013; 368: 20130122.

12. Zumft WG. Cell biology and molecular basis of denitrification. Microbiol Mol Biol Rev MMBR 1997; 61: 533-616. 
13. Wallenstein MD, Myrold DD, Firestone M, Voytek M. Environmental controls on denitrifying communities and denitrification rates: insights from molecular methods. Ecol Appl 2006; 16: 2143-2152.

14. Graf DRH, Jones CM, Hallin S. Intergenomic Comparisons Highlight Modularity of the Denitrification Pathway and Underpin the Importance of Community Structure for $\mathrm{N}_{2} \mathrm{O}$ Emissions. PLoS ONE 2014; 9: e114118.

15. Hallin S, Philippot L, Löffler FE, Sanford RA, Jones CM. Genomics and Ecology of Novel $\mathrm{N}_{2} \mathrm{O}$-Reducing Microorganisms. Trends Microbiol 2018; 26: 43-55.

16. Liu X-Y, Koba K, Koyama LA, Hobbie SE, Weiss MS, Inagaki Y, et al. Nitrate is an important nitrogen source for Arctic tundra plants. Proc Natl Acad Sci 2018; 115: 33983403.

17. Kou D, Yang G, Li F, Feng X, Zhang D, Mao C, et al. Progressive nitrogen limitation across the Tibetan alpine permafrost region. Nat Commun 2020; 11: 3331.

18. Yergeau E, Kang S, He Z, Zhou J, Kowalchuk GA. Functional microarray analysis of nitrogen and carbon cycling genes across an Antarctic latitudinal transect. ISME J 2007; 1: $163-179$.

19. Yergeau E, Hogues H, Whyte LG, Greer CW. The functional potential of high Arctic permafrost revealed by metagenomic sequencing, qPCR and microarray analyses. ISME $J$ 2010; 4: 1206-1214.

20. Palmer K, Biasi C, Horn MA. Contrasting denitrifier communities relate to contrasting $\mathrm{N}_{2} \mathrm{O}$ emission patterns from acidic peat soils in arctic tundra. ISME J 2012; 6: 1058-1077.

21. Dai H-T, Zhu R-B, Sun B-W, Che C-S, Hou L-J. Effects of Sea Animal Activities on Tundra Soil Denitrification and nirS- and nirK-Encoding Denitrifier Community in Maritime Antarctica. Front Microbiol 2020; 11: 573302.

22. Ortiz M, Bosch J, Coclet C, Johnson J, Lebre P, Salawu-Rotimi A, et al. Microbial Nitrogen Cycling in Antarctic Soils. Microorganisms 2020; 8: 1442.

23. Yu T, Zhuang Q. Quantifying global $\mathrm{N}_{2} \mathrm{O}$ emissions from natural ecosystem soils using traitbased biogeochemistry models. Biogeosciences 2019; 16: 207-222.

24. Rappé MS, Giovannoni SJ. The Uncultured Microbial Majority. Annu Rev Microbiol 2003; 57: 369-394.

25. Steen AD, Crits-Christoph A, Carini P, DeAngelis KM, Fierer N, Lloyd KG, et al. High proportions of bacteria and archaea across most biomes remain uncultured. ISME J 2019; 13: 3126-3130. 
26. Mackelprang R, Waldrop MP, DeAngelis KM, David MM, Chavarria KL, Blazewicz SJ, et al. Metagenomic analysis of a permafrost microbial community reveals a rapid response to thaw. Nature 2011; 480: 368-371.

27. Hultman J, Waldrop MP, Mackelprang R, David MM, McFarland J, Blazewicz SJ, et al. Multi-omics of permafrost, active layer and thermokarst bog soil microbiomes. Nature 2015; 521: 208-212.

28. Woodcroft BJ, Singleton CM, Boyd JA, Evans PN, Emerson JB, Zayed AAF, et al. Genomecentric view of carbon processing in thawing permafrost. Nature 2018; 560: 49-54.

29. Pirinen P, Simola H, Aalto J, Kaukoranta J-P, Karlsson P, Ruuhela R. Climatological statistics of Finland 1981-2010. 2012. Finnish Meteorological Institute, Helsinki.

30. le Roux PC, Aalto J, Luoto M. Soil moisture's underestimated role in climate change impact modelling in low-energy systems. Glob Change Biol 2013; 19: 2965-2975.

31. Niittynen P, Heikkinen RK, Aalto J, Guisan A, Kemppinen J, Luoto M. Fine-scale tundra vegetation patterns are strongly related to winter thermal conditions. Nat Clim Change 2020.

32. Viitamäki S, Pessi IS, Virkkala A-M, Niittynen P, Kemppinen J, Eronen-Rasimus E, et al. The activity and functions of subarctic soil microbial communities vary across vegetation types. bioRxiv 2021.

33. le Roux PC, Pellissier L, Wisz MS, Luoto M. Incorporating dominant species as proxies for biotic interactions strengthens plant community models. J Ecol 2014; 102: 767-775.

34. Kemppinen J, Niittynen P, Aalto J, le Roux PC, Luoto M. Water as a resource, stress and disturbance shaping tundra vegetation. Oikos 2019; 128: 811-822.

35. Livingston GP, Hutchinson GL. Enclosure-based measurement of trace gas exchange: applications and sources of error. Biogenic trace gases: Measuring emissions from soil and water. Blackwell Science, Oxford, United Kingdom, pp 14-51.

36. Andrews S. FastQC: A Quality Control Tool for High Throughput Sequence Data. 2019.

37. Ewels P, Magnusson M, Lundin S, Käller M. MultiQC: summarize analysis results for multiple tools and samples in a single report. Bioinformatics 2016; 32: 3047-3048.

38. Martin M. Cutadapt removes adapter sequences from high-throughput sequencing reads. EMBnet.journal 2011; 17: 10.

39. Leger A, Leonardi T. pycoQC, interactive quality control for Oxford Nanopore Sequencing. J Open Source Softw 2019; 4: 1236.

40. Wick RR. Porechop. 2018.

41. Li H. seqtk. 2018. 
42. Quast C, Pruesse E, Yilmaz P, Gerken J, Schweer T, Yarza P, et al. The SILVA ribosomal RNA gene database project: improved data processing and web-based tools. Nucleic Acids Res 2012; 41: D590-D596.

43. Bengtsson-Palme J, Hartmann M, Eriksson KM, Pal C, Thorell K, Larsson DGJ, et al. METAXA 2: improved identification and taxonomic classification of small and large subunit rRNA in metagenomic data. Mol Ecol Resour 2015; 15: 1403-1414.

44. Kanehisa M, Goto S. KEGG: Kyoto Encyclopedia of Genes and Genomes. Nucleic Acids Res 2000; 28: 27-30.

45. Buchfink B, Xie C, Huson DH. Fast and sensitive protein alignment using DIAMOND. Nat Methods 2015; 12: 59-60.

46. Pessi IS. keggR: a tool to parse the results of BLAST/DIAMOND similarity searches made against the KEGG GENES prokaryotes database. 2020.

47. R Core Team. R: A language and environment for statistical computing. 2020.

48. Oksanen J, Blanchet FG, Friendly M, Kindt R, Legendre P, McGlinn D, et al. vegan: Community Ecology Package. 2019.

49. Li D, Liu C-M, Luo R, Sadakane K, Lam T-W. MEGAHIT: an ultra-fast single-node solution for large and complex metagenomics assembly via succinct de Bruijn graph. Bioinformatics 2015; 31: 1674-1676.

50. Kolmogorov M, Bickhart DM, Behsaz B, Gurevich A, Rayko M, Shin SB, et al. metaFlye: scalable long-read metagenome assembly using repeat graphs. Nat Methods 2020.

51. Langmead B, Salzberg SL. Fast gapped-read alignment with Bowtie 2. Nat Methods 2012; 9: 357-359.

52. Li H, Handsaker B, Wysoker A, Fennell T, Ruan J, Homer N, et al. The Sequence Alignment/Map format and SAMtools. Bioinformatics 2009; 25: 2078-2079.

53. Walker BJ, Abeel T, Shea T, Priest M, Abouelliel A, Sakthikumar S, et al. Pilon: An Integrated Tool for Comprehensive Microbial Variant Detection and Genome Assembly Improvement. PLoS ONE 2014; 9: e112963.

54. Mikheenko A, Saveliev V, Gurevich A. MetaQUAST: evaluation of metagenome assemblies. Bioinformatics 2016; 32: 1088-1090.

55. Eren AM, Esen ÖC, Quince C, Vineis JH, Morrison HG, Sogin ML, et al. Anvi'o: an advanced analysis and visualization platform for 'omics data. PeerJ 2015; 3: e1319.

56. Hyatt D, Chen G-L, LoCascio PF, Land ML, Larimer FW, Hauser LJ. Prodigal: prokaryotic gene recognition and translation initiation site identification. BMC Bioinformatics 2010; 11: 119 .

57. Eddy SR. Accelerated Profile HMM Searches. PLoS Comput Biol 2011; 7: e1002195. 
58. Parks DH, Chuvochina M, Waite DW, Rinke C, Skarshewski A, Chaumeil P-A, et al. A standardized bacterial taxonomy based on genome phylogeny substantially revises the tree of life. Nat Biotechnol 2018; 36: 996-1004.

59. Parks DH, Chuvochina M, Chaumeil P-A, Rinke C, Mussig AJ, Hugenholtz P. A complete domain-to-species taxonomy for Bacteria and Archaea. Nat Biotechnol 2020.

60. Alneberg J, Bjarnason BS, de Bruijn I, Schirmer M, Quick J, Ijaz UZ, et al. Binning metagenomic contigs by coverage and composition. Nat Methods 2014; 11: 1144-1146.

61. Chaumeil P-A, Mussig AJ, Hugenholtz P, Parks DH. GTDB-Tk: a toolkit to classify genomes with the Genome Taxonomy Database. Bioinformatics 2019; btz848.

62. Edgar RC. MUSCLE: multiple sequence alignment with high accuracy and high throughput. Nucleic Acids Res 2004; 32: 1792-1797.

63. Price MN, Dehal PS, Arkin AP. FastTree 2-Approximately Maximum-Likelihood Trees for Large Alignments. PLoS ONE 2010; 5: e9490.

64. Aramaki T, Blanc-Mathieu R, Endo H, Ohkubo K, Kanehisa M, Goto S, et al. KofamKOALA: KEGG Ortholog assignment based on profile HMM and adaptive score threshold. Bioinformatics 2020; 36: 2251-2252.

65. Zhang H, Yohe T, Huang L, Entwistle S, Wu P, Yang Z, et al. dbCAN2: a meta server for automated carbohydrate-active enzyme annotation. Nucleic Acids Res 2018; 46: W95W101.

66. Decleyre H, Heylen K, Tytgat B, Willems A. Highly diverse nirK genes comprise two major clades that harbour ammonium-producing denitrifiers. BMC Genomics 2016; 17: 155.

67. Li Y, Bali S, Borg S, Katzmann E, Ferguson SJ, Schuler D. Cytochrome cd1 Nitrite Reductase NirS Is Involved in Anaerobic Magnetite Biomineralization in Magnetospirillum gryphiswaldense and Requires NirN for Proper d1 Heme Assembly. J Bacteriol 2013; 195: 4297-4309.

68. Heylen K, Keltjens J. Redundancy and modularity in membrane-associated dissimilatory nitrate reduction in Bacillus. Front Microbiol 2012; 3.

69. Katoh K, Standley DM. MAFFT Multiple Sequence Alignment Software Version 7: Improvements in Performance and Usability. Mol Biol Evol 2013; 30: 772-780.

70. Okonechnikov K, Golosova O, Fursov M. Unipro UGENE: a unified bioinformatics toolkit. Bioinformatics 2012; 28: 1166-1167.

71. Jain C, Rodriguez-R LM, Phillippy AM, Konstantinidis KT, Aluru S. High throughput ANI analysis of $90 \mathrm{~K}$ prokaryotic genomes reveals clear species boundaries. Nat Commun 2018; 9: 5114.

72. Woodcroft BJ. CoverM. 
73. Li H. Minimap and miniasm: fast mapping and de novo assembly for noisy long sequences. Bioinformatics 2016; 32: 2103-2110.

74. Borisov VB, Gennis RB, Hemp J, Verkhovsky MI. The cytochrome bd respiratory oxygen reductases. Biochim Biophys Acta BBA - Bioenerg 2011; 1807: 1398-1413.

75. Giuffrè A, Borisov VB, Arese M, Sarti P, Forte E. Cytochrome bd oxidase and bacterial tolerance to oxidative and nitrosative stress. Biochim Biophys Acta BBA - Bioenerg 2014; 1837: $1178-1187$.

76. Dinamarca MA, Ruiz-Manzano A, Rojo F. Inactivation of Cytochrome o Ubiquinol Oxidase Relieves Catabolic Repression of the Pseudomonas putida GPo1 Alkane Degradation Pathway. J Bacteriol 2002; 184: 3785-3793.

77. Bueno E, Mesa S, Bedmar EJ, Richardson DJ, Delgado MJ. Bacterial Adaptation of Respiration from Oxic to Microoxic and Anoxic Conditions: Redox Control. Antioxid Redox Signal 2012; 16: 819-852.

78. Sanford RA, Wagner DD, Wu Q, Chee-Sanford JC, Thomas SH, Cruz-Garcia C, et al. Unexpected nondenitrifier nitrous oxide reductase gene diversity and abundance in soils. Proc Natl Acad Sci 2012; 109: 19709-19714.

79. Makhalanyane TP, Van Goethem MW, Cowan DA. Microbial diversity and functional capacity in polar soils. Curr Opin Biotechnol 2016; 38: 159-166.

80. Anantharaman K, Brown CT, Hug LA, Sharon I, Castelle CJ, Probst AJ, et al. Thousands of microbial genomes shed light on interconnected biogeochemical processes in an aquifer system. Nat Commun 2016; 7: 13219.

81. Diamond S, Andeer PF, Li Z, Crits-Christoph A, Burstein D, Anantharaman K, et al. Mediterranean grassland soil C-N compound turnover is dependent on rainfall and depth, and is mediated by genomically divergent microorganisms. Nat Microbiol 2019; 4: 13561367.

82. Sun X, Ward BB. Novel metagenome-assembled genomes involved in the nitrogen cycle from a Pacific oxygen minimum zone. ISME Commun 2021; 1: 26.

83. Lilja EE, Johnson DR. Segregating metabolic processes into different microbial cells accelerates the consumption of inhibitory substrates. ISME J 2016; 10: 1568-1578.

84. Westergaard-Nielsen A, Balstrøm T, Treier UA, Normand S, Elberling B. Estimating meltwater retention and associated nitrate redistribution during snowmelt in an Arctic tundra landscape. Environ Res Lett 2020; 15: 034025.

85. Delgado-Baquerizo M, Oliverio AM, Brewer TE, Benavent-González A, Eldridge DJ, Bardgett RD, et al. A global atlas of the dominant bacteria found in soil. Science 2018; 359: $320-325$. 
86. Männistö MK, Kurhela E, Tiirola M, Häggblom MM. Acidobacteria dominate the active bacterial communities of Arctic tundra with widely divergent winter-time snow accumulation and soil temperatures. FEMS Microbiol Ecol 2013; 84: 47-59.

87. Costello EK, Schmidt SK. Microbial diversity in alpine tundra wet meadow soil: novel Chloroflexi from a cold, water-saturated environment. Environ Microbiol 2006; 8: 14711486.

88. Davis KER, Sangwan P, Janssen PH. Acidobacteria, Rubrobacteridae and Chloroflexi are abundant among very slow-growing and mini-colony-forming soil bacteria. Environ Microbiol 2011; 13: 798-805.

89. Losey NA, Stevenson BS, Busse H-J, Damsté JSS, Rijpstra WIC, Rudd S, et al. Thermoanaerobaculum aquaticum gen. nov., sp. nov., the first cultivated member of Acidobacteria subdivision 23, isolated from a hot spring. Int J Syst Evol Microbiol 2013; 63: $4149-4157$.

90. Lycus P, Lovise Bøthun K, Bergaust L, Peele Shapleigh J, Reier Bakken L, Frostegård Å. Phenotypic and genotypic richness of denitrifiers revealed by a novel isolation strategy. ISME J 2017; 11: 2219-2232.

91. Park D, Kim H, Yoon S. Nitrous Oxide Reduction by an Obligate Aerobic Bacterium, Gemmatimonas aurantiaca Strain T-27. Appl Environ Microbiol 2017; 83.

92. Klemedtsson L, Von Arnold K, Weslien P, Gundersen P. Soil CN ratio as a scalar parameter to predict nitrous oxide emissions. Glob Change Biol 2005; 11: 1142-1147.

93. Philippot L, Andert J, Jones CM, Bru D, Hallin S. Importance of denitrifiers lacking the genes encoding the nitrous oxide reductase for $\mathrm{N}_{2} \mathrm{O}$ emissions from soil: role of denitrifier diversity for N2O fluxes. Glob Change Biol 2011; 17: 1497-1504.

94. Jones CM, Graf DR, Bru D, Philippot L, Hallin S. The unaccounted yet abundant nitrous oxide-reducing microbial community: a potential nitrous oxide sink. ISME J 2013; 7: 417426.

95. Jones CM, Spor A, Brennan FP, Breuil M-C, Bru D, Lemanceau P, et al. Recently identified microbial guild mediates soil $\mathrm{N}_{2} \mathrm{O}$ sink capacity. Nat Clim Change 2014; 4: 801-805.

96. Bakken LR, Bergaust L, Liu B, Frostegård Å. Regulation of denitrification at the cellular level: a clue to the understanding of $\mathrm{N}_{2} \mathrm{O}$ emissions from soils. Philos Trans $R$ Soc B Biol Sci 2012; 367: 1226-1234. 
bioRxiv preprint doi: https://doi.org/10.1101/2020.12.21.419267; this version posted June 30, 2021. The copyright holder for this preprint

(which was not certified by peer review) is the author/funder, who has granted bioRxiv a license to display the preprint in perpetuity. It is made available under aCC-BY-NC-ND 4.0 International license.

\section{Supplementary Figures}

(Previous page) Suppl. Fig. S1 | Saana Nature Reserve, an area of mountain tundra in Kilpisjärvi, northern Finland. a) Map of Fennoscandia showing the location of Kilpisjärvi. b) Aerial overview of the study area showing the location of the 43 sites sampled for metagenomic analysis. Image provided by the National Land Survey of Finland under the Creative Commons CC BY 4.0 license. c) Pictures of the four types of soil ecosystems investigated. d) Physicochemical characterization of the soil ecosystems based on an extended set of 228 samples taken from the organic layer. e) In situ ecosystem-level nitrous oxide $\left(\mathrm{N}_{2} \mathrm{O}\right)$ and methane $\left(\mathrm{CH}_{4}\right)$ fluxes measured from 101 sites using a static, non-steady state, non-flowthrough system. Negative values represent net uptake and positive net emissions. 
bioRxiv preprint doi: https://doi.org/10.1101/2020.12.21.419267; this version posted June 30, 2021. The copyright holder for this preprint (which was not certified by peer review) is the author/funder, who has granted bioRxiv a license to display the preprint in perpetuity. It is made available under aCC-BY-NC-ND 4.0 International license.
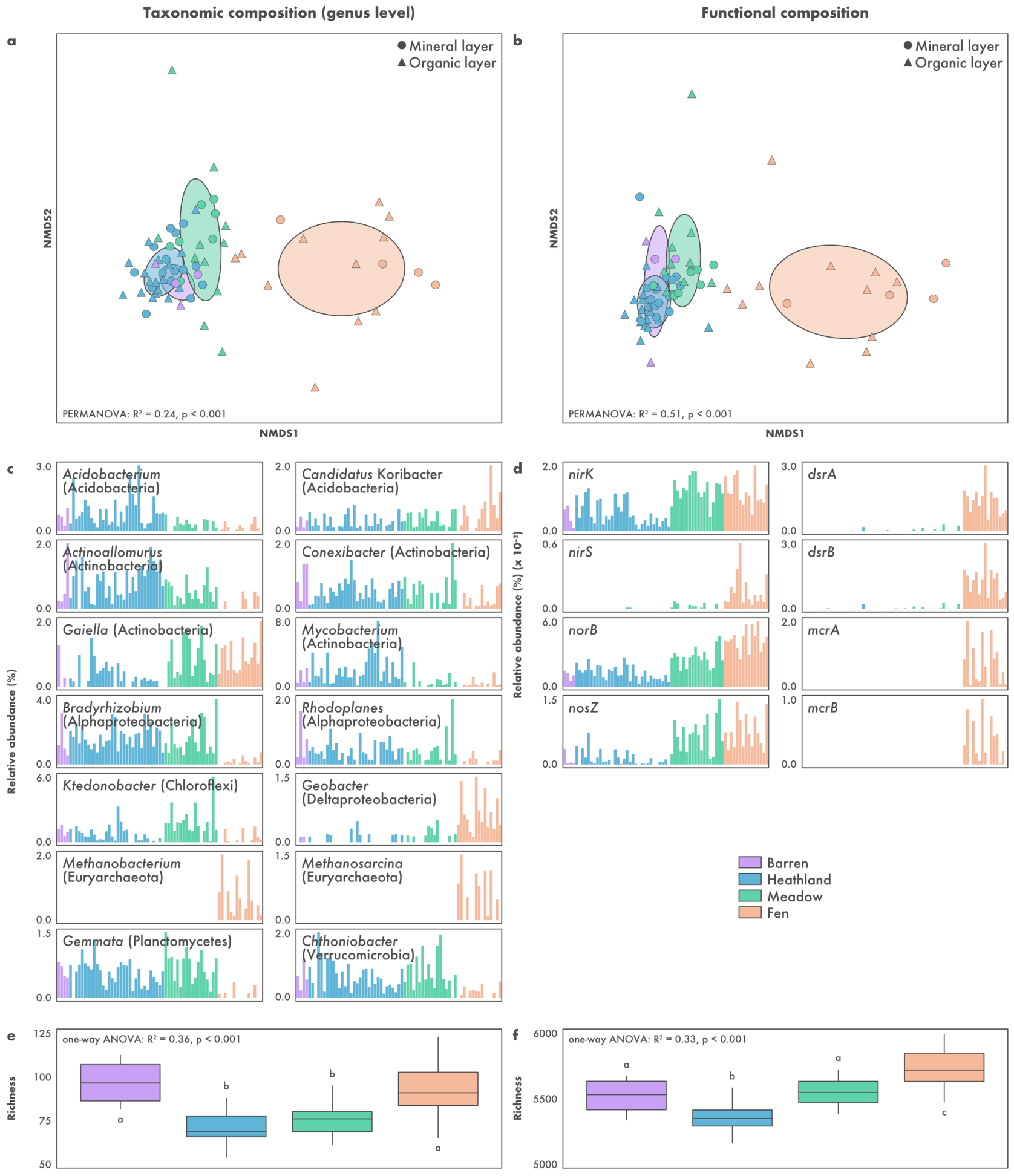
(Previous page) Suppl. Fig. S2 | The microbial diversity of Kilpisjärvi soils as seen using a read-based approach. Read-based analyses were carried out using unassembled Illumina data. Taxonomic composition was computed based on the annotation of SSU rRNA gene sequences against the SILVA database with METAXA. Functional annotation was performed by blastx searches against the KEGG database with DIAMOND. a, b) Non-metric multidimensional scaling (NMDS) of taxonomic and functional community structure, respectively. Differences between the ecosystems were assessed using permutational ANOVA (PERMANOVA). c) Abundance profile of the five most abundant genera in each ecosystem. d) Abundance profile of marker genes for denitrification, sulfate reduction, and methanogenesis. e, f) Taxonomic (number of genera) and functional (number of functional genes) richness. Differences in richness were assessed using one-way ANOVA followed by

Tukey's HSD test. Ecosystems that do not share the same letter are significantly different. 
bioRxiv preprint doi: https://doi.org/10.1101/2020.12.21.419267; this version posted June 30, 2021. The copyright holder for this preprint

(which was not certified by peer review) is the author/funder, who has granted bioRxiv a license to display the preprint in perpetuity. It is made available under aCC-BY-NC-ND 4.0 International license.
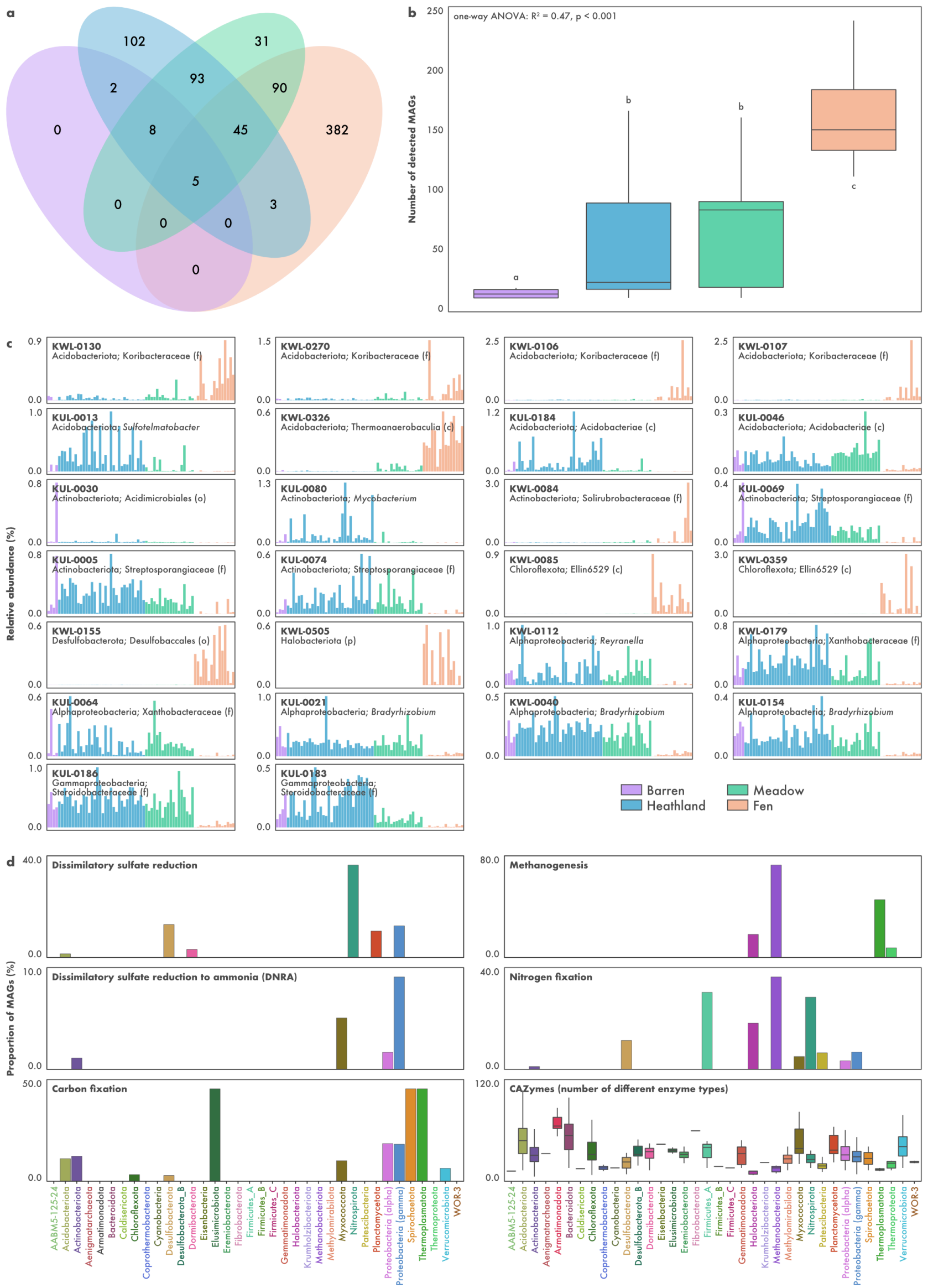
(Previous page) Suppl. Fig. S3 | Overview of the microbial diversity in Kilpisjärvi soils based on a genome-resolved approach. a) Number of metagenome-assembled genomes (MAGs) shared between the different ecosystems. b) Number of detected MAGs across the ecosystems. c) Relative abundance of the ten most abundant MAGs in each ecosystem, computed as a proportion of reads mapping to each MAG. d) Metabolic potential of the MAGs based on the annotation of genes against the KOfam database. Barplots represent the proportion of MAGs in each phylum with complete pathways, i.e. containing $\geq 75 \%$ of the genes in the pathway. Boxplots of carbohydrate-active enzymes (CAZymes) show the number of different enzyme types identified in each MAG. 
bioRxiv preprint doi: https://doi.org/10.1101/2020.12.21.419267; this version posted June 30, 2021. The copyright holder for this preprint (which was not certified by peer review) is the author/funder, who has granted bioRxiv a license to display the preprint in perpetuity. It is made available under aCC-BY-NC-ND 4.0 International license.

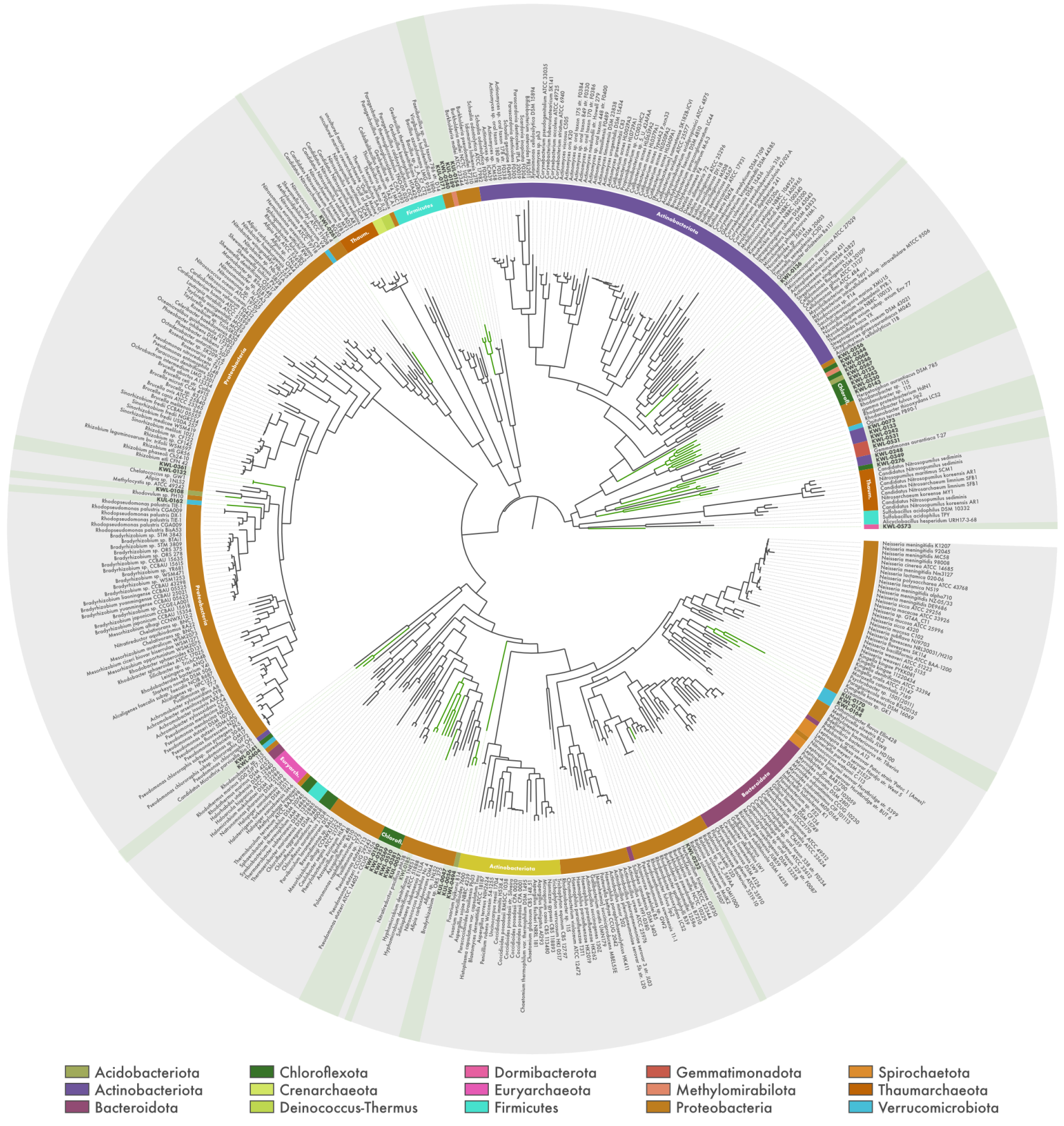
(MAGs) recovered from tundra soils in Kilpisjärvi, northern Finland. Midpoint-rooted maximum-likelihood tree of translated nirK sequences from Kilpisjärvi MAGs (highlighted) along with reference sequences from archaeal and bacterial genomes. 
bioRxiv preprint doi: https://doi.org/10.1101/2020.12.21.419267; this version posted June 30, 2021. The copyright holder for this preprint (which was not certified by peer review) is the author/funder, who has granted bioRxiv a license to display the preprint in perpetuity. It is made available under aCC-BY-NC-ND 4.0 International license.

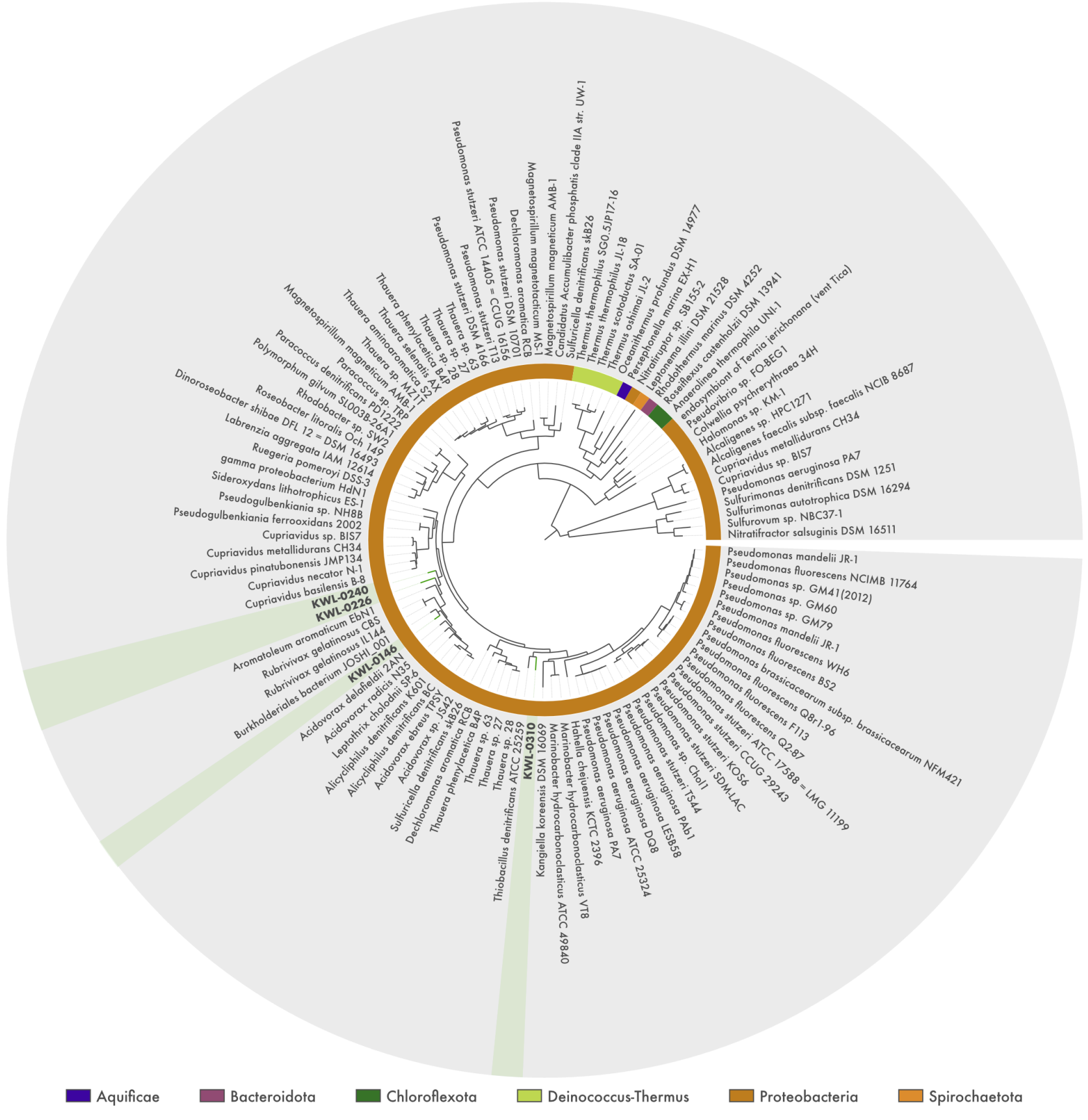
along with reference sequences from archaeal and bacterial genomes. 
bioRxiv preprint doi: https://doi.org/10.1101/2020.12.21.419267; this version posted June 30, 2021. The copyright holder for this preprint (which was not certified by peer review) is the author/funder, who has granted bioRxiv a license to display the preprint in perpetuity. It is made available under aCC-BY-NC-ND 4.0 International license.

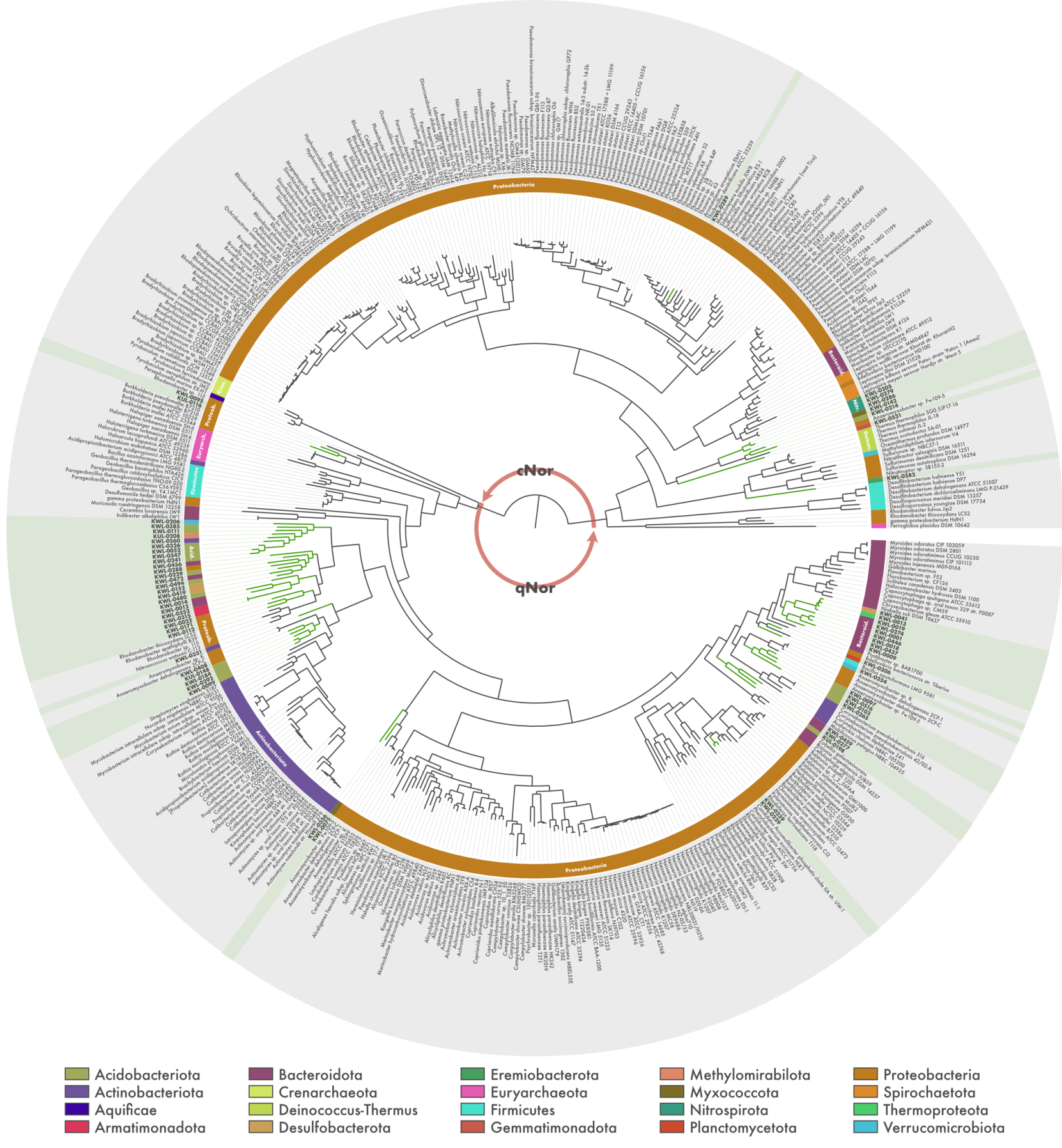

Suppl. Fig. S6 | Phylogeny of norB sequences from metagenome-assembled genomes (MAGs) recovered from tundra soils in Kilpisjärvi, northern Finland. Midpoint-rooted maximum-likelihood tree of translated norB sequences from Kilpisjärvi MAGs (highlighted) along with reference sequences from archaeal and bacterial genomes. 
bioRxiv preprint doi: https://doi.org/10.1101/2020.12.21.419267; this version posted June 30, 2021. The copyright holder for this preprint (which was not certified by peer review) is the author/funder, who has granted bioRxiv a license to display the preprint in perpetuity. It is made available under aCC-BY-NC-ND 4.0 International license.

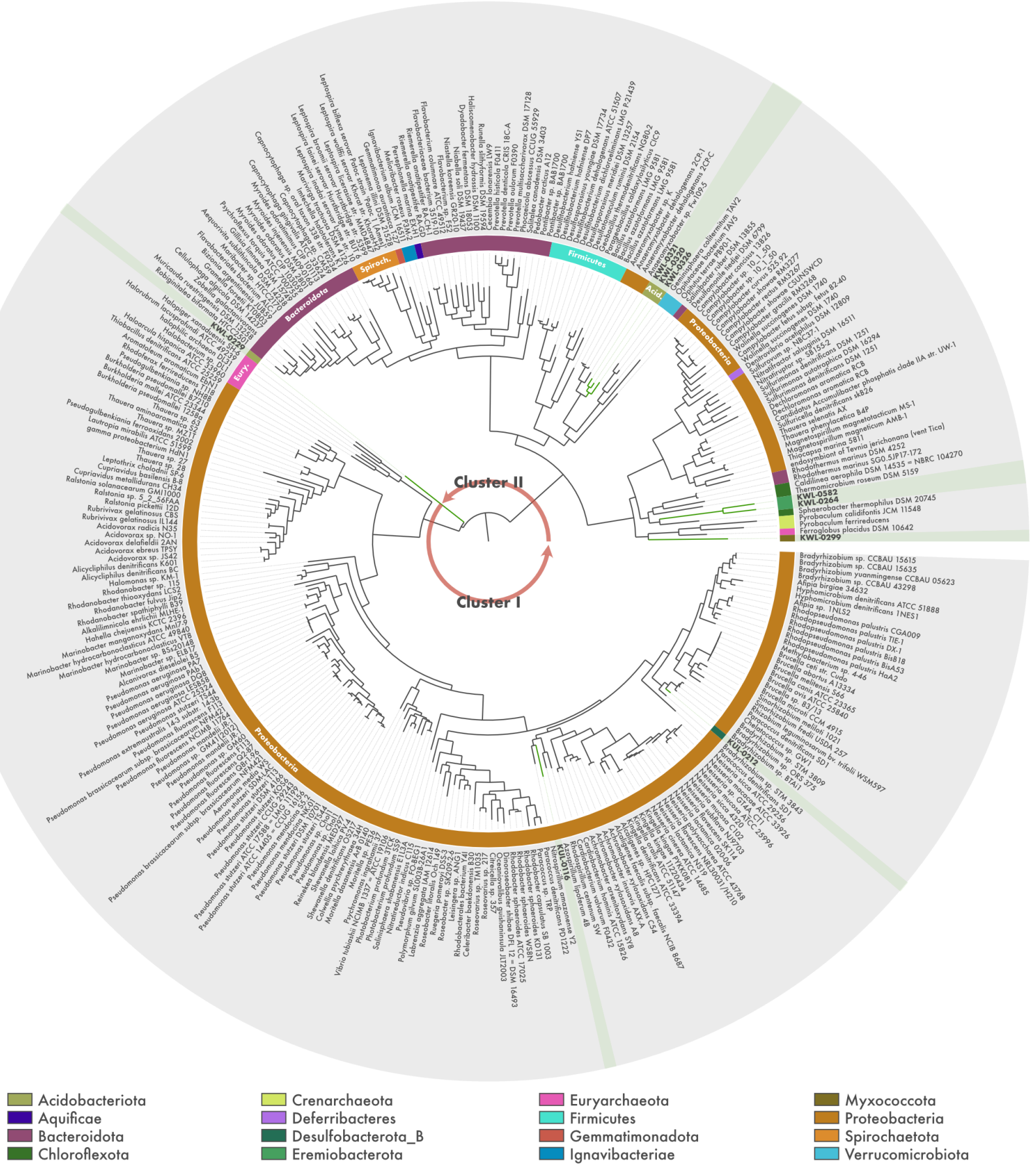

Suppl. Fig. S7 | Phylogeny of nosZ sequences from metagenome-assembled genomes (MAGs) recovered from tundra soils in Kilpisjärvi, northern Finland. Midpoint-rooted maximum-likelihood tree of translated nos $Z$ sequences from Kilpisjärvi MAGs (highlighted) along with reference sequences from archaeal and bacterial genomes. 
bioRxiv preprint doi: https://doi.org/10.1101/2020.12.21.419267; this version posted June 30, 2021. The copyright holder for this preprint (which was not certified by peer review) is the author/funder, who has granted bioRxiv a license to display the preprint in perpetuity. It is made available under aCC-BY-NC-ND 4.0 International license.

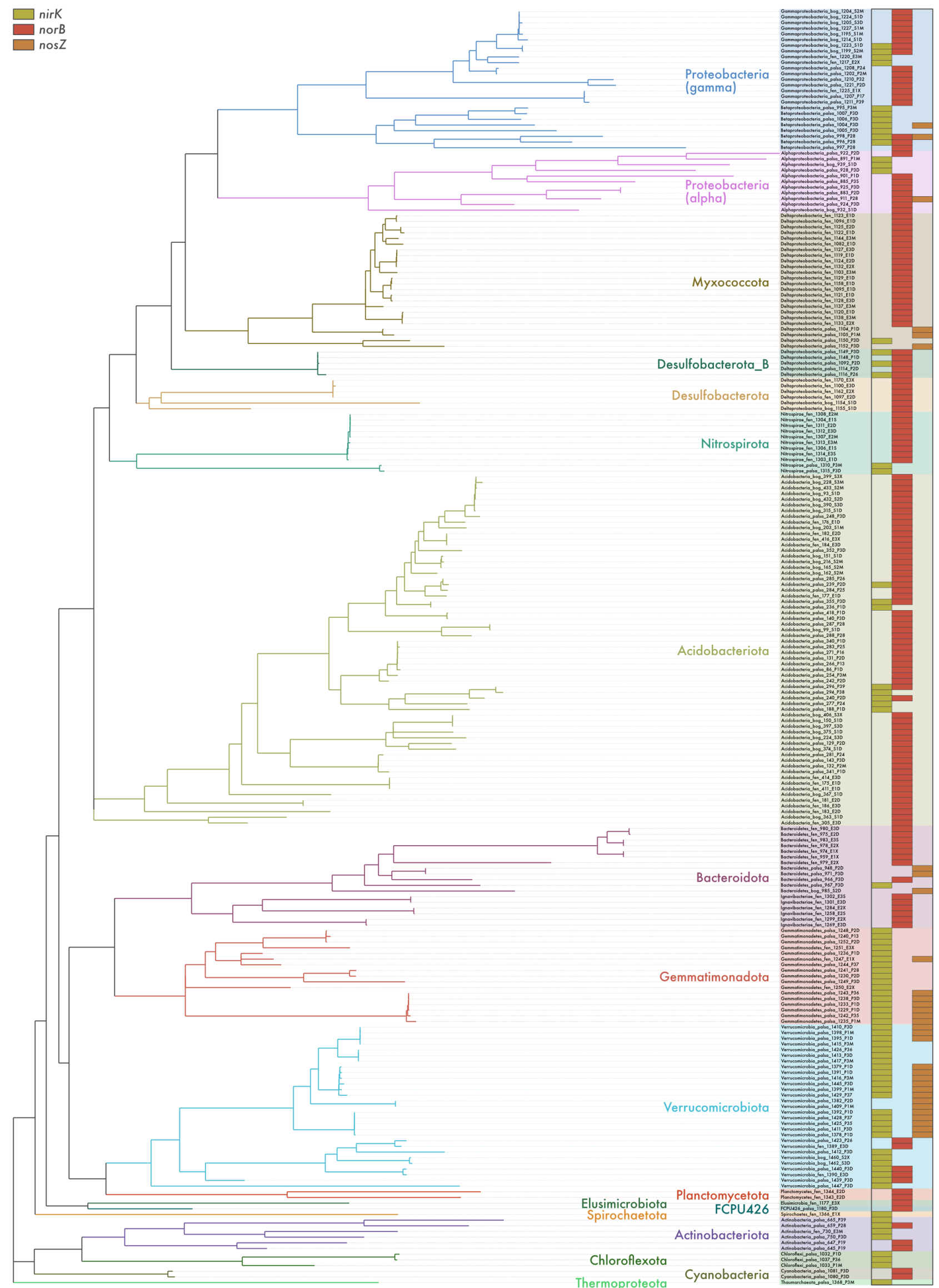


(Previous page) Suppl. Fig. S8 | Metabolic potential for denitrification in Stordalen

Mire soils. Distribution of denitrification genes across 225 metagenome-assembled genomes (MAGs) from permafrost peatland, bog, and fen soils in Stordalen Mire, northern Sweden. Genes encoding the nitrite (nirK), nitric oxide (nor $B$ ), and nitrous oxide (nosZ) reductases were annotated using a three-step approach including (1) identification using hidden Markov models from the KOfam database, (2) manual inspection for the presence of conserved residues at positions associated with the binding of co-factors and active sites, and (3) phylogenetic analyses along with sequences from archaeal and bacterial genomes. Phylogenomic analysis of MAGs was done based on concatenated alignments of amino acid sequences from 122 archaeal and 120 bacterial single-copy genes. 
bioRxiv preprint doi: https://doi.org/10.1101/2020.12.21.419267; this version posted June 30, 2021. The copyright holder for this preprint (which was not certified by peer review) is the author/funder, who has granted bioRxiv a license to display the preprint in perpetuity. It is made available under aCC-BY-NC-ND 4.0 International license.

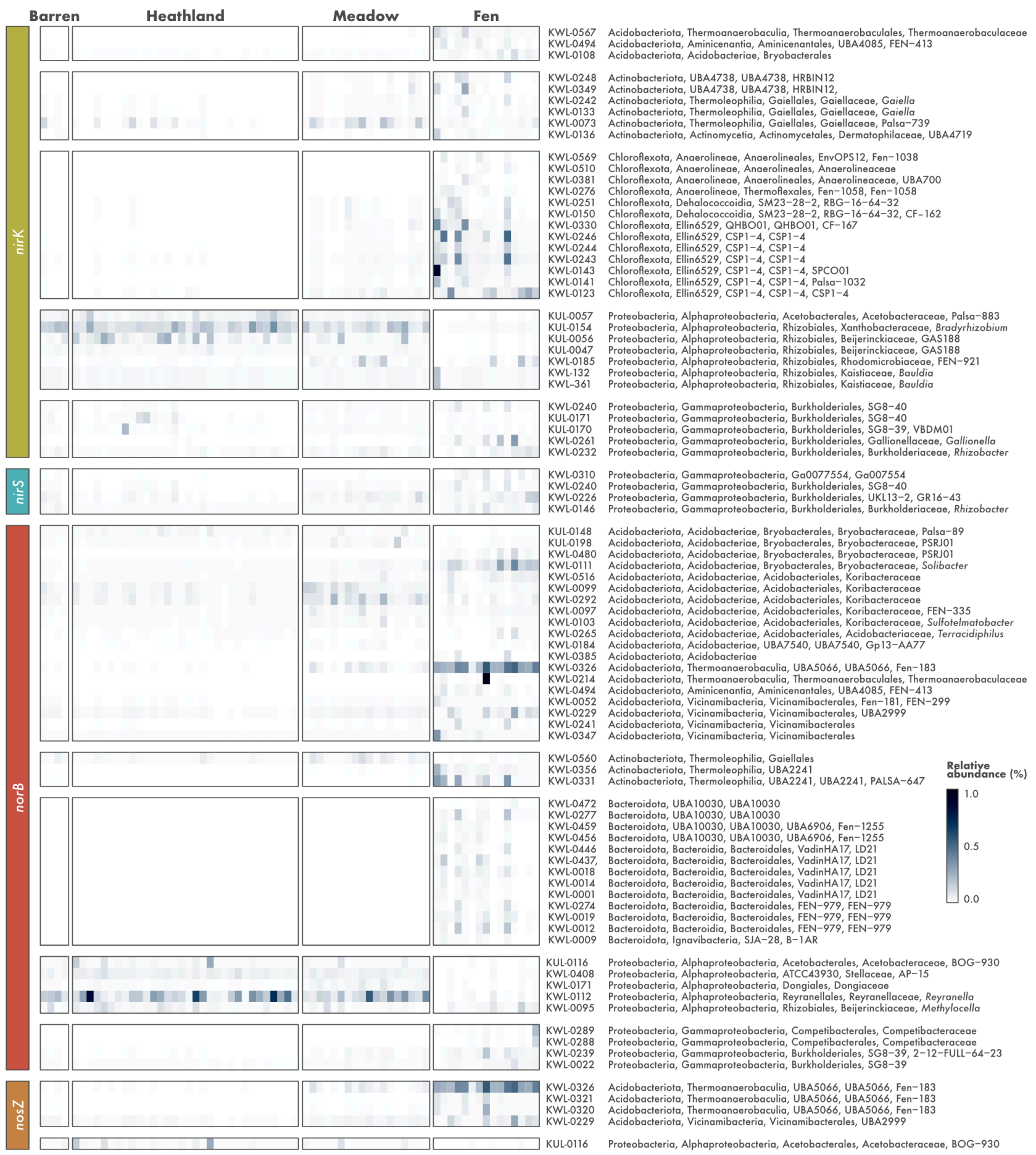

Suppl. Fig. S9 | Relative abundance of metagenome-assembled genomes (MAGs) harbouring denitrification genes across different soil ecosystems in the tundra. MAGs were recovered from soils in Kilpisjärvi, northern Finland, and annotated for genes encoding the nitrite (nirK/nirS), nitric oxide (norB), and nitrous oxide (nosZ) reductases using a threestep approach. Relative abundances were computed as a proportion of reads mapping to each MAG. 